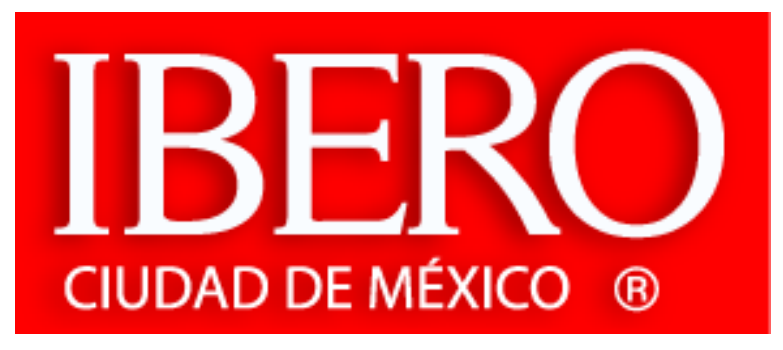

Departamento de Economía Serie documentos de trabajo 2013

Determinants of Regional Growth by Manufacturing Sector in Mexico, 1988-2008

Mariana Pereira-López

Isidro Soloaga

Agosto 2013

Documento de trabajo No. 7, 2013 


\title{
Determinants of Regional Growth by Manufacturing Sector in Mexico, 1988-2008
}

\begin{abstract}
This article presents an empirical analysis aimed at identifying the determinants of regional growth in Mexico by manufacturing sector in the period 1988-2008. In the framework of agglomeration economies it argues that the main factor behind Mexico's long-term regional industrial growth is Jacobs externalities (urbanization economies), and that wages are the main short-term factor behind this growth. There is heterogeneity in the determinants of regional growth according to technological intensity. Lowtechnology sectors appear to be more sensitive to initial wages and exhibit Jacobs externalities, while higher technology sectors show Porter economies (competition/specialization). Controlling for market conditions, agglomeration economies, and initial conditions, the south, the center and the Gulf of Mexico have a relative disadvantage for growth in medium-high-technology sectors. Moreover, only one out of the 58 Metropolitan Areas (MAs) studied shows a relative advantage for growth in this kind of industry. Relative advantage for low-technology sectors appears to be related to transportation and service infrastructure, while for high-technology sectors the main determinant is human capital.
\end{abstract}

Keywords:agglomeration, regional growth, knowledge spillovers, dynamic externalities, Mexico JEL Classification: R1

Mariana Pereira-López (marianappl@gmail.com)

Isidro Soloaga (isidro.soloaga@ibero.mx)

Universidad Iberoamericana Ciudad de México

October, 2013 


\section{Determinants of Regional Growth by Manufacturing Sector in Mexico, 1988-2008}

\section{Introduction}

The location choices of firms can help to explain why some countries have been successful in terms of growth while others have lagged. Recent work has therefore focused on the benefits of agglomeration and location: knowledge spillovers, linkages, congestion and market access, among other considerations. ${ }^{2}$ As Amiti and Cameron (2007) and Moretti (2011) argue, these factors could explain why, under the assumption that firms minimize costs, some remain in higher wage regions. While market conditions (wages, housing prices, etc.) could give firms an incentive to leave certain locations, externalities and agglomeration benefits may create incentives to remain there.

In the case of Mexico, studies such as Hanson (1998) emphasize transportation costs as the driver of industrial location and agglomeration. If this is the case, firms should tend to concentrate along the northern border of the country. However, following Mexico's trade opening in the late 1980s, industrial location patterns have changed in a way that suggests that other factors may be at work. As shown in Figure 1, during the last twenty years, low technology sectors have moved from the center of the country to the south, while medium-high technology sectors have tended to move north. This behavior is consistent with a laddering process in which firms are moving from one region to another and being replaced by industries of higher technological intensity or with more value added.

The analysis of agglomeration economies is also of great importance due to its implications for economic policy: knowing the factors that firms value in choosing a location would lead to a more effective policy design to attract investment. It is likewise important to analyze the dynamics of these factors: what Henderson et al. (1995) regard as dynamic externalities, because it is possible to identify the effect of historical advantages on the current location of industries. Although there is still much debate regarding the nature of externalities, there is consensus on the existence of long-term agglomeration effects. The literature identifies three different kinds of effects: i) Jacobs economies, which are externalities generated by other industries or urbanization

\footnotetext{
${ }^{2}$ Studies by Glaeser, Kallal, Scheinkman, and Shleifer (1992) and Henderson, Kuncoro, and Turner (1995) are the most influential.
} 
and under which competition is positive for growth; ii) Marshall-Arrow-Romer (MAR) economies, which are intra-industry externalities or specialization benefits which can be internalized by monopolies that are therefore beneficial for growth; and iii) Porter externalities, in which specialized industries incentivize growth and local competition enhances the adoption of technology.

FIGURE 1. MA'S SHARE OF NATIONAL EMPLOYMENT IN THE SECTOR *

Low technology

a) Apparel
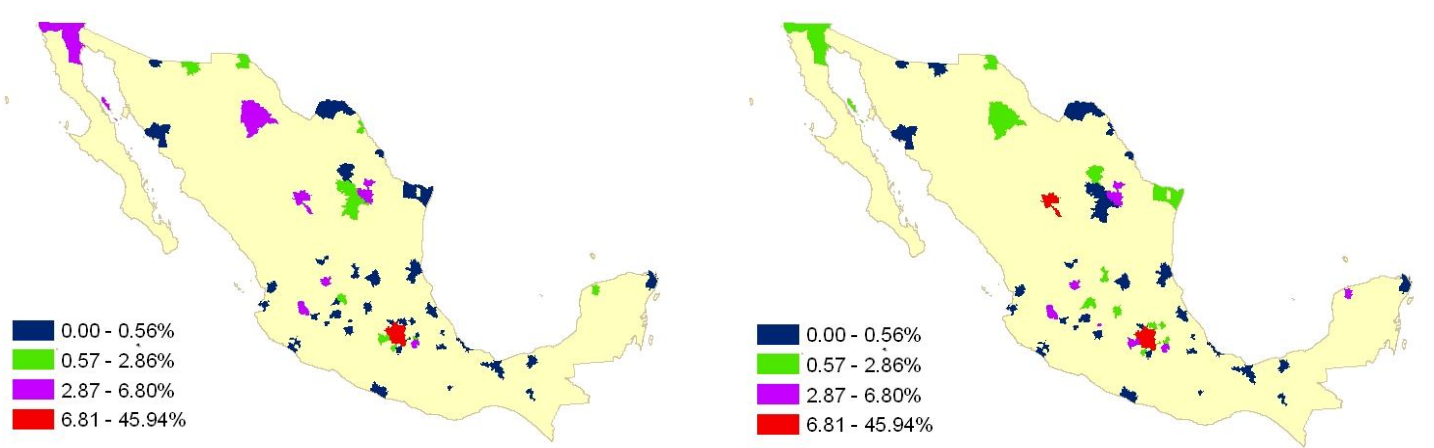

Medium-high technology

e) Electrical appliances

1988

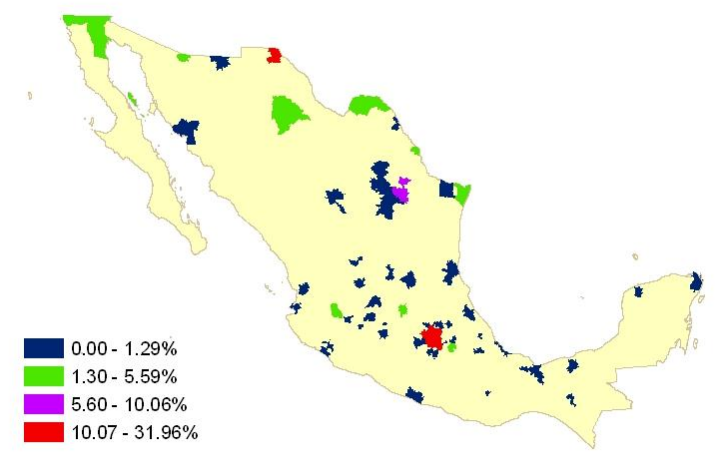

2008

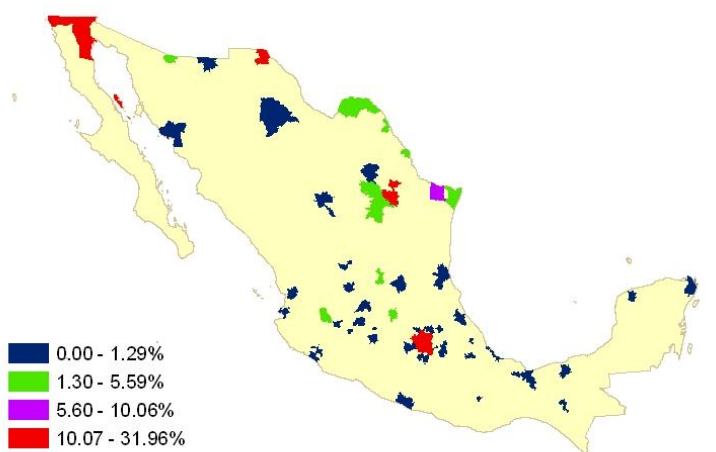

*The sectors shown were selected as an example of each technological group.

The sum of all areas for each year is $100 \%$.

Source: Author's calculations with data from the 1989 and 2009 Economic Censuses, INEGI.

This article analyzes the factors that affect regional growth across manufacturing sectors in Mexico: market conditions (using wages as an instrument) or knowledge spillovers, and if the latter, which of the three types of agglomeration economies are observed: intra-industry (MAR), inter-industry (Jacobs), or Porter. Additionally, it establishes whether, controlling for market 
conditions and agglomeration economies, certain regions still exhibit a disadvantage for growth. To address these questions, it starts from the hypothesis that there are sectoral differences in the factors that affect industrial growth in particular regions, which should be associated with technological intensity. Moreover, for low-technology sectors market conditions should prevail, while for higher-technology sectors externalities or agglomeration benefits should have more weight.

This paper's contribution consists, first, in analyzing the determinants of regional growth by manufacturing sector in Mexico, an insufficiently studied topic in which almost always trade opening has been considered the driving force. Second, it emphasizes sectoral differences, principally in technological intensity; unlike other studies, it does not assume that different sectors should exhibit similar behavior. Third, it analyzes relative advantages and disadvantages for regions or MAs (fixed effects), which are generally used only as control variables but which could have policy implications. Finally, it considers the presence of the maquiladora industry as a characteristic of anMA that may affect industrial location or labor demand growth and is, therefore, a control variable. ${ }^{3}$

The main conclusions are that in the long term, Jacobs (urbanization) economies are the main factor behind regional growth by manufacturing sector, while wages are more relevant in the short term. There is heterogeneity regarding regional growth determinants, related to technological intensity. Low-technology sectors are relatively more sensitive to initial wages and, in terms of agglomeration economies, exhibit Jacobs externalities, while higher technology sectors show Porter economies (competition/specialization). Controlling for market conditions, agglomeration economies, and initial conditions, the south, the center and the Gulf of Mexico still have a relative disadvantage for medium-high technology sectors that cannot be compensated by changes in agglomeration variables. Moreover, in the analysis of MAs, only one seems to have a relative advantage for medium-high technology sectors. Relative advantage for low-technology sectors appears to be related to transportation and service infrastructure, while for higher-technology sectors the main determinant is human capital.

The paper is organized as follows: section 2 includes a literature review of agglomeration economies and studies of Mexico. Section 3 details the model that is used as a basis for empirical

\footnotetext{
${ }^{3}$ Even though the maquiladora sector was of great importance, representing almost 48\% of Mexico's exports in 2000 (Hanson, 2003) the only study for Mexico seeking to control for it is Hanson (1998).
} 
estimates. In section 4, the methodology and data are presented. Results are discussed in section 5 and conclusions in section 6.

\section{Literature review}

\subsection{The New Economic Geography and agglomeration economies}

As Harris (2011) argues, the New Economic Geography (NEG) emerges as a consequence of the New Trade Theory (NTT) developed by Krugman (1991), Krugman and Venables (1995) and Fujita, Krugman, and Venables (1999) and it is mainly a regional extension of trade between countries aimed at explaining industrial clusters formation and focusing on transportation costs and industrial linkages.

In order to explain agglomerations, the basic models in the framework of the NEG, developed mainly by Krugman and Venables, assume Spence-Dixit-Stiglitz monopolistic competition with increasing returns to scale and product differentiation. As Harris (2011) says, depending on their assumptions, some of these models generate a core-periphery pattern, that is, an equilibrium with agglomeration and in which activity is not uniformly distributed; other models predict differential growth rates and divergent trends; and furthermore, some models suggest initial divergence and later convergence in growth rates.

Centripetal and centrifugal forces play a crucial role in the results of these models. According to Glaeser and Gottlieb (2009) centripetal forces can be classified in three categories: (1) transportation costs, (2) labor market depth, and (3) ideas transference.

In terms of transportation costs, the theory developed mainly by Krugman (1991), indicates that agglomeration reduces costs from moving goods in the space, which has a direct relation to backward and forward linkages.

Regarding labor market depth, in a diversity of analyses following Marshall (1890), emphasis is made on the costs reduction for employers, due to labor pooling in one region. At the same time, uncertainty is reduced for the labor force, allowing workers to make riskier choices due to the decrease in search costs and the better matching between employers and employees. Finally, if very specific abilities are required, workers have more incentives to acquire them in a region in

which there is a variety of firms that could demand them. At the same time with a larger pool of specialized workers in a region, the probability of firms using that kind of ability increases. In 
this sense, this literature is closely related to the one that analyzes the dynamics of the labor market and the wage ratio between skilled and unskilled workers. ${ }^{4}$

Regarding the transference of ideas, this theory arises as a result of Jacobs' (1969) work and it states that agglomerations accelerate the flow of ideas. This is related with the previous group of theories, as the movement of workers between firms, enhances the transference of ideas and innovation and increases individual human capital. According to Glaeser and Gottlieb (2009), the existence of human capital spillovers is suggested by the positive correlation between wages and abilities in a city as well as by the connection between abilities and population growth in a city. Additionally, Rodrik (2004) argues that certain firms could observe the success of other firms in the same sector of activity and, as a result of geographical proximity, decide to copy these best practices.

In this sense, the literature distinguishes two types of agglomeration externalities: localization economies and urbanization economies. The first type, also known as MarshallArrow-Romer (MAR) economies, are those externalities that arise in the same industry, that is, when firms of the same industryagglomerate in a region or city. ${ }^{5}$ The second type, regarded as Jacobs economies, are inter-industry externalities and are based on the assumption that diversity (a great deal of firms of different sectors or industries) generates innovation. As Harris (2011) argues, there is no consensus regarding which of these two types of externalities is more relevant for industrial location and growth.

MAR economies predict that local monopolies enhance growth, as the flow of ideas can be restricted and, at the same time, knowledge spillovers can be internalized (Glaeser et al., 1992). In this sense, these same authors consider a third type of externalities, based on Porter (1990), which as MAR, argues that specialized and geographically concentrated industries enhance growth, but considers that local competition is the force behind growth and technology adoption (see Figure 2 for a summary of agglomeration economies).

\footnotetext{
${ }^{4}$ See Esquivel, Lustig, and Scott (2010) for an example regarding Mexico in the framework of this literature.

${ }^{5}$ An example of these intra-industry agglomerations, are high-technology firms in the U.S. concentrated in Silicon Valley, as well as automotive firms located in Detroit.
} 
FIGURE 2. CHARACTERISTICS OF AGGLOMERATION ECONOMIES

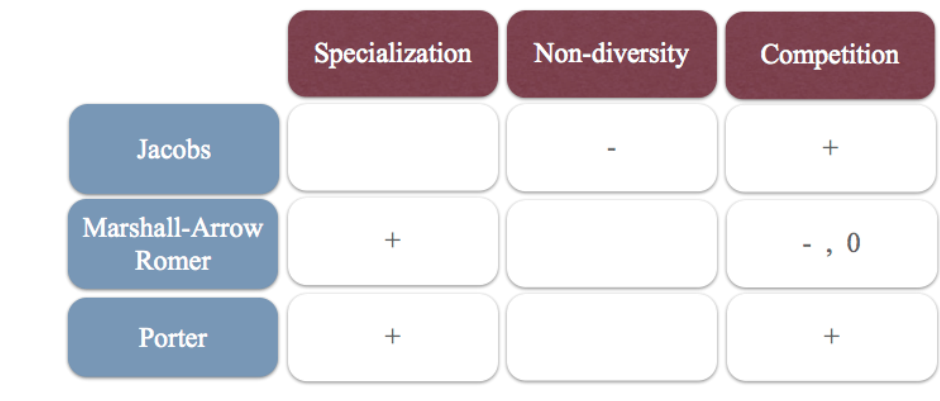

Source: Author's elaboration with information from Glaeser et al. (1992)

Recent empirical studies in this field emphasize the centripetal force associated with the transference of ideas or knowledge spillovers, without excluding the possibility of the three forces operating simultaneously.

Just as there are factors that incentivize clusters or agglomerations, there are centrifugal or repelling forces associated to agglomerations that generate costs that must be compensated through higher wages. Among these forces are congestion and pollution. Additionally, due to labor mobility, agglomeration translates into higher prices of immobile factors such as land and housing.

\subsection{Empirical studies on agglomeration economies}

The two most influential empirical papers in this literature are Glaeser et al. (1992) and Henderson et al. (1995) and both of them analyze industries-cities in the U.S. The first authors find Jacobs (urbanization) economies and that intra-industry externalities, measured by specialization, seem to negatively affect long-term growth, contrary to the predictions of MAR theories. Henderson et al. (1995) analyze mature and new high-technology industries and find that urbanization economies are significant for new industries, which also exhibit intra-industry externalities, but not for the ones already established.

Van Oort (2007)carries out a similar analysis for the Netherlands, taking also into account spatial heterogeneity and finds results consistent with Glaeser et al. (1992) in favor of urbanization economies. Van Stel and Nieuwenhuijsen (2004) have similar results for the same 
country, but for the manufacturing industry the determinant turns out to be competition. Battisse (2002) studies agglomeration in the case of China, finding results similar to the ones in Glaeser et al. (1992), but this author also finds that growth dynamics differ between coastal zones and mainland China.

For Spain, De Lucio, Herce, and Goicolea (2002) evaluate agglomeration economies by sector of the manufacturing industry and find evidence of MAR externalities. Acs, FitzRoy, and Smith (2002) find results in the same line for high-technology industries in the U.S.

In general, even though there is evidence of agglomeration economies, the results regarding the nature of these externalities are not conclusive. However, there is a bias towards MAR economies when higher-technology industries are considered.

\subsection{Empirical studies on industrial location and agglomeration economies for Mexico}

There is no much research for Mexico in the framework of the NEG and agglomeration economies, and most of the studies focus on the trade opening strategy. One of the most influential is Krugman and Livas (1996) and these authors conclude that trade barriers before 1986, that is the import substitution model, generated an excessive agglomeration in Mexico City. In this same line, Hanson (1998) finds that trade openness has moved industrial clusters from the center to the north of the country. These articles emphasize transportation costs as the crucial factor that incentivize firms to locate in the north while existent agglomeration reinforces the pre-trade-opening pattern. Results in Mendoza-Cota and Pérez-Cruz (2007), and DiazBautista $(2005)^{6}$ are consistent with this approach.

Félix Verduzco (2005) analyzes the effects of agglomeration economy on economic growth for the period of 1988-1998 and concludes that there are externalities from specialization and diversity for the whole country, mainly in the long term, but results change once the analysis is limited to the north, as these factors are no longer significant. Mendoza-Cota (2002) also focuses on the northern border and concludes that there are specialization effects, especially between 1988 and 1993 and that there are little positive effects of diversity on the GDP per capita growth of these cities.

\footnotetext{
${ }^{6}$ This author includes migration among the factors that determine growth, which is a questionable assumption due to endogeneity problems between agglomeration and migration.
} 
Byemphasizing the role of trade opening, these studies predict well the movements to the north, but they fail to explain the movement of certain industries to the center and south, which could be related to agglomeration effects.

\section{Theoretical framework}

Starting from the simple model of Glaeser et al. (1992) in which the production function $Q$ for each firm in sectori, location $j$ and time tis given by:

$$
Q_{i j t}=A_{i j t} f\left(l_{i j t}, \ldots\right)
$$

Where:

$A_{i j t}=$ Technology in industry $i$, location $j$ and time $t$ in nominal terms (it includes technological changes as well as price changes)

$l_{i j t}=$ Employment in industry $i$, location $j$ and time $t$

$f()=$. Specific functional form of the production function.

Each firm considers industry technology, prices and wages as given and maximizes benefits when the labor marginal product equals wages. Using the simple functional form included in Glaeser et al. (1992) $f(l)=l^{1-\alpha}, 0<\alpha<1$ :

$w_{i j t}=A_{i j t} f^{\prime}\left(l_{i j t}, \ldots\right)=A_{i j t}(1-\alpha) l_{i j t}^{-\alpha}$

It is assumed that technology has a national and a local component:

$$
A_{i j t}=A_{i, l o c a l, t} A_{i, n a t i o n a l, t}
$$

In terms of growth rates between $t-\tau$ and $t$ :

$$
\ln \left(\frac{A_{i j, t}}{A_{i j, t-\tau}}\right)=\ln \left(\frac{A_{i, n a t i o n a l, t}}{A_{i, \text { national }, t-\tau}}\right)+\ln \left(\frac{A_{i, l o c a l, t}}{A_{i, \text { local }, t-\tau}}\right)
$$

Following Griliches (1979) and Jaffe (1989), it is assumed that there is a production function of technological change and local innovation (the second term in the right side of equation 3.4). That is:

$$
\ln \left(\frac{A_{i, l o c a l, t}}{A_{i, l o c a l, t-\tau}}\right)=f\left(\lambda R \& D_{i, j, t-\tau}, N_{i, j, t-\tau}\right)
$$

Where:

$\lambda<1$ as not all investments translate into innovation. $R \& D=$ Expenditure in Research \&Development (R\&D) 
$N_{i, j, t-\tau}=$ Number of firms in industry $i$, location $j$ and time $t-\tau$. This term is included following the literature on $\mathrm{R} \& \mathrm{D}$, in which as the number of researchers increases, more technological innovation is generated.

Under the assumptions that investment in $\mathrm{R} \& \mathrm{D}$ is a proportion $\omega$ of employment in the previous period, which is plausible in the context of learn by doing, and that firms maximize their benefits independently of what they spend on R\&D, equation 3.5 can be written as:

$$
\ln \left(\frac{A_{i, l o c a l, t}}{A_{i, l o c a l, t-\tau}}\right)=f\left(\lambda \omega l_{i, j, t-\tau}, N_{i, j, t-\tau}\right)
$$

It is assumed that once new knowledge or innovation is generated, it becomes a public good (with no rivalry in consumption and it is difficult to exclude other firms or agents), which is consistent with endogenous growth models. With this assumption, technology generated by other sector and/or locations can be used, but its adoption depends on the ability of the firm or sector to do it. Adding this assumption to equation 3.6 leads to:

$$
\begin{aligned}
\ln \left(\frac{A_{i, \text { local }, t}}{A_{i, \text { local }, t-\tau}}\right)= & f\left(\lambda \omega l_{i, j, t-\tau}, N_{i, j, t-\tau}, \sum_{m \neq j} \theta_{1, m} \lambda \omega l_{i, m, t-\tau}, \sum_{k \neq i} \theta_{2, k} \lambda \omega l_{k, j, t-\tau}, \sum_{k \neq i} \sum_{m \neq j} \theta_{3, k, m} \lambda \omega l_{k, m, t-\tau}\right) \\
& \text { (1) (2) (3) (4) (5) }
\end{aligned}
$$

Where:

$\theta_{1, m}=$ Part of innovation generated by the same industry $i$ in other locations that can be adopted by industry $i$ in location $j$. This parameter varies depending on the distance between locations.

$\theta_{2, k}=$ Part of innovation generated by other industries in location $j$ that can be adopted by industry $i$ in location $j$. This parameter varies depending on industries affinity.

$\theta_{3, k, m}=$ Part of innovation generated by other industries in other locations that can be adopted by industryiin location $j$. This parameter varies depending on the distance between locations and industries affinity.

Taking the first and the third terms of equation 3.7, a specialization index can be constructed; this indicator reflects the importance of an industry in a location relative to its importance in other locations. The second term in the equation (number of firms in the sectorlocation) can be easily related to competition. The fourth and fifth term can be used to generate a diversity indicator, reflecting the importance of other industries in location $j$ relative to their importance in all other locations.

Thus, equation (3.7) can be simplified to the form presented in Glaeser et al. $(1992)^{7}$, in which they model local technology growth as a function of specialization, competition, diversity

\footnotetext{
${ }^{7}$ See De Lucio et al. (2002) for a different model to obtain the equation in Glaeser et al. (1992)
} 
and initial conditions, which allowed them to test empirically different types of agglomeration (MAR, Jacobs and Porter):

$$
\ln \left(\frac{A_{i, l o c a l, t}}{A_{i, l o c a l, t-\tau}}\right)=g(\text { specialization, competition, diversity, initial conditions })
$$

Expressing equation (3.2) in terms of growth rates and substituting the results of (3.4) and (3.8), and solving for employment growth $\left(l_{i j}\right)$ :

$\ln \left(\frac{l_{i, j, t}}{l_{i, j, t-\tau}}\right)=-\frac{1}{\alpha} \ln \left(\frac{w_{i, j, t}}{w_{i, j, t-\tau}}\right)+\frac{1}{\alpha} \ln \left(\frac{A_{i, \text { national }, t}}{A_{i, \text { national }, t-\tau}}\right)$

$+\frac{1}{\alpha} g($ specialization, competition, diversity, initial conditions)(3.9)

\section{Empirical Strategy}

\subsection{Data}

This paper used information from the last five Economic Censuses (1989, 1994, 1999, 2004 and 2009) at the municipality level. Thesedata was concentrated at the MA level according to the INEGI/ CONAPO/SEDESOL MA classification of $2000 .^{8}$ Three additional MA's were includeddue to their participation in the maquiladora industry employment during the 90's. (See Appendix 1 for the MAs structure).

This level of aggregation is used as there is a higher probability that industrial location decisions as well as knowledge spillovers occur at this level. That is, in the boundary between two municipalities, one firm could be indifferent between locating in any of them, as long as they are in the same MA; however, locating in different MAs could have different implications regarding services, infrastructure, amenities, etc.

As Table 1 shows, restricting the sample to 58 MA's, more than $70 \%$ of the manufacturing employment reported in economic censuses is covered. Accordingly, 18 sectors of the manufacturing industry were considered. (See Appendix 2 for the sectoral structure). ${ }^{9}$

\footnotetext{
${ }^{8}$ The 2000 MA classification is used instead of the 2005 classification, since changes in the structure of an MA could be related to its industrial growth. That is, the 2005 could be endogenous with respect to the model.

${ }^{9}$ In other studies for Mexico, such as Mendoza-Cota (2002) and Mendoza-Cota and Perez Cruz (2007), more disaggregated sectors are used due to the change in product classifications (the 1989 and 1995 Economic Censuses use CMAP while the 1999 and 2009 ones use NAICS). In this case, the compatibility between classifications was checked using the 1999 Economic Census as a basis, as the data is available for both classifications. The correlation between the sectoral employment using CMAP and NAICS is 0.93.
} 
TABLE 1. SHARE OF MAS IN MANUFACTURING EMPLOYMENT

\begin{tabular}{llc}
\cline { 2 - 2 } & \multicolumn{2}{c}{ Employment } \\
1988 & $81.2 \%$ \\
1993 & $78.1 \%$ \\
1998 & $76.9 \%$ \\
2003 & $75.1 \%$ \\
2008 & $74.3 \%$ \\
\hline Source: Author's calculions using data from the 1989, 1994, 1999 and 2004 \\
Economic Censuses, INEGI.
\end{tabular}

\subsection{Econometric specification}

Following Glaeser et al. (1992), under the following assumptions:

1) Workers participate in a national labor market. Therefore, wage growth will be constant across MAs, making initial wages the only relevant variable.

2) Knowledge spillovers are constant through time affecting both new and already established industries in the same magnitude. If this is not the case, the function or the parameters should be different between new and already established sectors and between high-technology and low-technology sectors.

The validity of these two assumptions will be tested later.

Starting from equation 3.9, the following specification is used:

$$
\begin{aligned}
& \ln \left(\frac{l_{i j, t}}{l_{i j, t-\tau}}\right)=\beta_{0}+\beta_{1} l_{i j, t-\tau}+\beta_{2} \ln \left(\frac{\sum_{k \neq j}^{J} l_{i k, t}}{\sum_{k \neq j}^{J} l_{i k, t-\tau}}\right)+\beta_{3} w_{i j, t-\tau}+\beta_{4} \rho_{i j, t-\tau}+\beta_{5} c_{i j, t-\tau}+\beta_{6} d_{i j, t-\tau} \\
& +\beta_{7} m a q_{i j, t-\tau}+\alpha_{R} R_{j}+e_{i j, t}
\end{aligned}
$$

Where:

$l_{i j, t-\tau}=$ Employment of sector $i$, in location $j$ in time $t-\tau$

$\ln \left(\frac{\sum_{k \neq j}^{J} l_{i k, t}}{\sum_{k \neq j}^{J} l_{i k, t-\tau}}\right)=$ Employment growth in sectori in the rest of the MAs

$w_{i j, t-\tau}=$ Average wage of sectori, in location $j$ in time $t-\tau$

$\rho_{i j, t-\tau}=$ Concentration or specialization index of sector $i$ in location $j$ in time $t-\tau$.

$c_{i j, t-\tau}=$ Competition index of sector $i$ in location $j$ in time $t-\tau$

$d_{i j, t-\tau}=$ Non-diversity index of sector $i$ in location $j$ in time $t-\tau$

$m a q_{i j, t-\tau}=$ Share of location $j$ in the maquiladora-industry employment in time $t-\tau$

$R_{j}=$ Regional dummies 
The construction of the agglomeration indicators is as follows:

Concentration or specialization index: This measure is given by the relative share of sector $i$ in location $j$ versus the same sector's share in the national industry. An MA which is more specialized in sector $i$, exhibits a higher ratio.

$$
\rho_{i j, t-\tau}=\frac{\frac{l_{i j, t-\tau}}{\sum_{i} l_{i j, t-\tau}}}{\frac{\sum_{j} l_{i j, t-\tau}}{\sum_{i} \Sigma_{j} l_{i j, t-\tau}}}
$$

A positive and significant parameter could indicate either MAR or Porter economies, depending on the competition index. (See Figure 2 for the summary of these characteristics).

Competition:Number of establishments per worker in industry $i$ and location $j$ with respect to the number of establishments per worker in that same industry for the whole country. That is, this variable indicates whether more firms per worker exist in that location compared to the national average, which implies more competition. Positive and significant coefficients for this measure could be associated with both Jacobs and Porter economies, while negative or non-significant coefficients could indicate MAR economies.

$$
C_{i j, t-\tau}=\frac{\frac{e_{i j, t-\tau}}{l_{i j, t-\tau}}}{\frac{\sum_{j} e_{i j, t-\tau}}{\sum_{j} l_{i j, t-\tau}}}(4.3)
$$

Diversity: This indicator is used to assess whether having a set of different industries is important in order to enhance growth (Jacobs economies). As a measure of diversity, the indicator suggested by Henderson et al. (1995) is calculated, which is based on a Hirschman-Herfindahl Index (HHI):

$$
H H I_{i j, t-\tau}=\sum_{k \neq i}^{I} s_{k j, t-\tau}^{2}=\sum_{k \neq i}^{I}\left(\frac{l_{k j, t-\tau}}{\sum_{k \neq i}^{I} l_{k j, t-\tau}}\right)^{2}
$$

This index takes the sum of the squares of the shares of all the other sectors in local employment. An increase in this index means less diversity; in the extreme case where the rest of the economic activity isconcentrated in one sector, this indicator will have a value of one. ${ }^{10}$

\footnotetext{
${ }^{10}$ Glaeser et al. (1992) use the share of the other five main firms in local employment. A higher value of this variable indicates more diversity. In this case, this indicator was not used as it can have a low value either because the first six industries do not concentrate much of the initial local employment (in which case there really is a great deal of diversity) or because the industry concentrates much of the employment in that location (in which case there
} 
Therefore, the first two variables in equation (4.1) are controls: $\beta_{1}$ is the convergence parameter, widely used in growth equations, and $\beta_{2}$ captures the effect of national demand on industry $i$. The parameters of interest are $\beta_{3}-\beta_{7}$. The effect of wages (initial market conditions) on labor demand growth, which is captured by $\beta_{3}$ is expected to be negative. $\beta_{4}$ is the effect of specialization and is expected to be positive in the case of MAR or Porter economies. $\beta_{5}$ is the competition parameter and under Porter or Jacobs economies it should have a positive sign, while under MAR it should be negative or non significant. The effect of diversity, which is related to Jacobs economies should be captured by $\beta_{6}$ and its sign is expected to be negative as an increase of the HHI is related to a reduction in diversity. (See Figure 2 for the expected effects in agglomeration variables)

$\beta_{7}$ is the parameter associated to the share of the MA in the maquiladora industry employment. Following Hanson (1998) and due to the importance of this industry during Mexico's trade opening process, it is important to control for it. ${ }^{11} R_{j}$ are regional dummies, which allow to control for region-specific policies or transportation costs. ${ }^{12}$

Under this specification, which uses growth rates in the left side, observations in which employment in one sector-MA was zero are not included. However, only 97 of the 1,044 observations that represent less than one percent of total employment in 2008 have this characteristic.

Equation 4.1 is estimated for two values of $\tau$ : 1) $\tau=20$, in which only information from the 1989 and 2009 censuses is used; and 2) $\tau=5$, where data from the five last censuses is used $\left(1989,1994,1999,2004\right.$ y 2009). ${ }^{13}$

is no diversity). Additionally, it would reduce the sample to the main six sectors only. As a robustness test, the equation was estimated using the Theil Index as a non-diversity measure.

${ }^{11}$ Hanson (1998) uses women's employment in the state-sector as proxy for the importance of the maquiladora industry, as these industries used to employ a higher proportion of women. This methodology is not followed here as the share of women has increased for all industries.

12 The regions used are defined by INEGI (see Appendix 1 for the detail). Alternatively, the following specification is estimated where MA effects are included $(F j)$ :

$$
\begin{aligned}
\ln \left(\frac{l_{i j, t}}{l_{i j, t-\tau}}\right)=\beta_{0} & +\beta_{1} l_{i j, t-\tau}+\beta_{2} \ln \left(\frac{\sum_{k \neq j}^{J} l_{i k, t}}{\sum_{k \neq j}^{J} l_{i k, t-\tau}}\right)+\beta_{3} \ln \left(w_{i j, t-\tau}\right)+\beta_{4} \rho_{i j, t-\tau}+\beta_{5} c_{i j, t-\tau}+\beta_{6} d_{i j, t-\tau} \\
& +\beta_{7} m a q_{i j, t-\tau}+\alpha_{F} F_{j}+e_{i j, t}
\end{aligned}
$$

\footnotetext{
${ }^{13}$ In order to assess the robustness of the results, the model is estimated using System Generalized Method of Moments (GMM).
} 
As the focus of this study is on sectoral differences, the equation was estimated by technological intensity ${ }^{14}$, using the OECD classification (see Appendix 3 for this classification), which is exogenous to the data. In this case, seemingly unrelated regressions (SUR) are estimated and Chow tests are used in order to test the hypothesis that parameters are different between the different groups.

Results can be divided in two. First, parameters are analyzed in terms of market conditions and agglomeration. Second, fixed effects from these models are discussed.

\subsection{Descriptive statistics}

As can be seen in Figure 3, the density of employment by MA shows that most of the observations take low values. That is, a few MAs concentrate most of the employment. This is consistent with what in urban economics is regarded as Zipf's Law ${ }^{15}$, which states that there is always a higher density of small cities. This is important because estimates will thus include a great deal of observations with low weights in terms of employment. Therefore it is essential to control for the initial value of employment.

FIGURE 3. KERNEL DENSITY OF TOTAL MANUFACTURING EMPLOYMENT BY MA

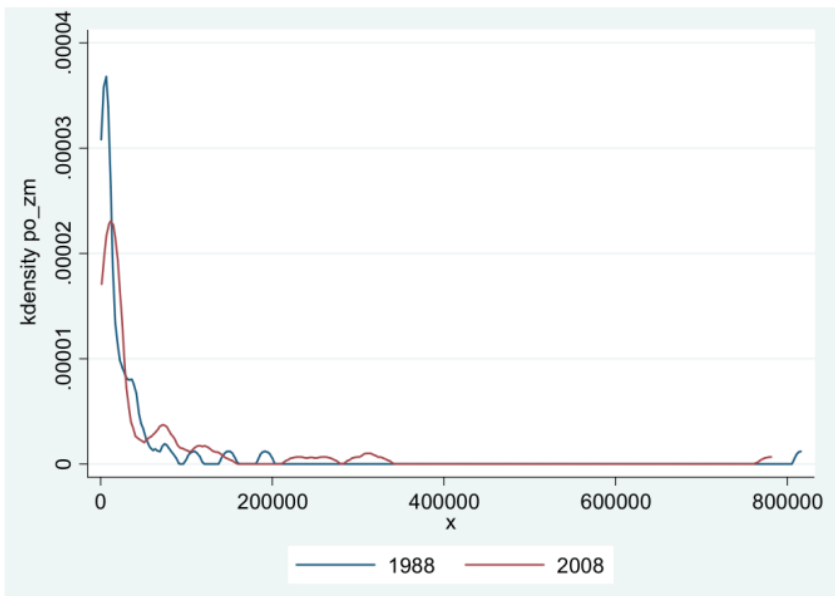

Source: Author's calculations using data from the 1989 and 2009 economic censuses, INEGI.

\footnotetext{
${ }^{14}$ Results were also obtained at the sectoral level but are not shown because in some MAs there is no presence of some sectors, which reduces the degrees of freedom in the regression analysis. These tables are available upon request.

${ }^{15}$ See Gabaix (1999) for further details on Zipf’s Law.
} 
Regarding the distribution of employment by technological intensity, as Figure 4 shows, the shares of each intensity group in total employment have remained relatively stable, indicating that even though low-technology sectors have the largest share, the three groups have shown similar growth patterns.

FIGURE 4. SHARE OF MANUFACTURING EMPLOYMENT BY TECHNOLOGICAL INTENSITY

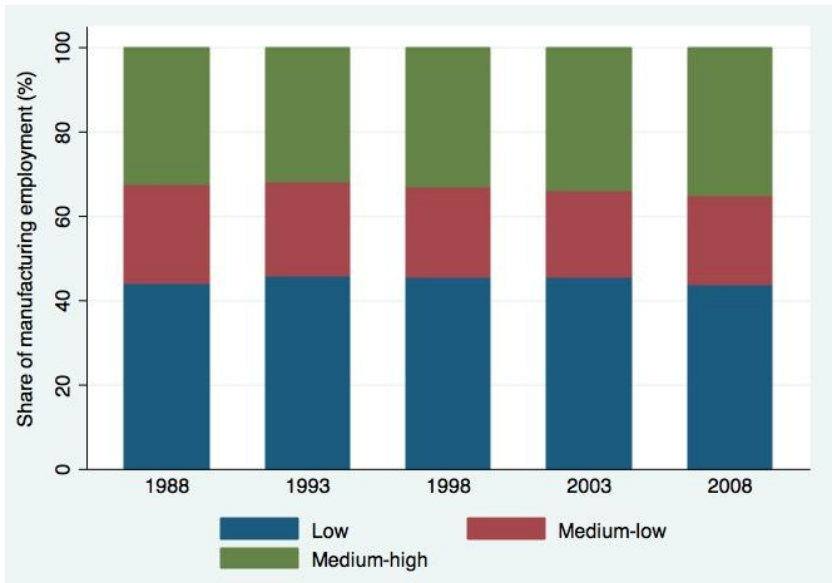

Source: Author's calculations with data from the 1989, 1994, 1999, 2004 and 2009 Economic Censuses, INEGI.

Figure 5 shows whether employment in an MA is growing in the same sectors in which national demand is increasing (using employment growth in the rest of the regions as a proxy). For example, for the north region, employment grows in the same sectors as national demand. However, in the case of medium-high technology sectors, such as electric machinery and equipment, employment in this region is growing, while in other regions there is little change; this could indicate that the north is a leader region. The central-north region shows a similar but less marked trend. In the case of the Capital region, employment decreases are observed in a group of sectors in which other regions exhibit growth, which reflects the decentralization experienced in recent years. Although the Gulf of Mexico is growing in industries in which other regions exhibit growth too, in some high-technology sectors such as the chemical sector it is decreasing while other regions are growing. 
FIGURE 5. GROWTH IN EMPLOYMENT AGAINST THE REST OF THE REGIONS *
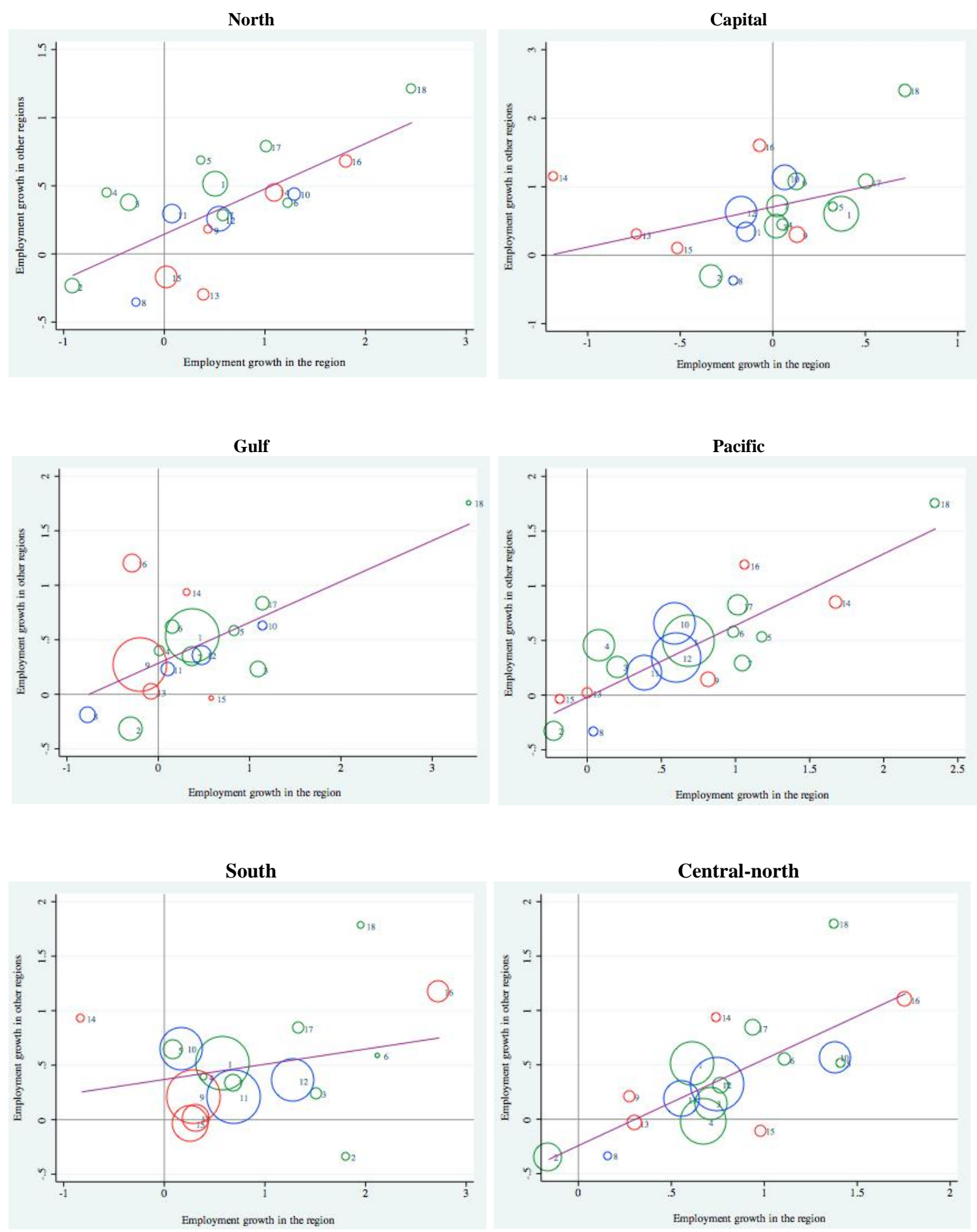


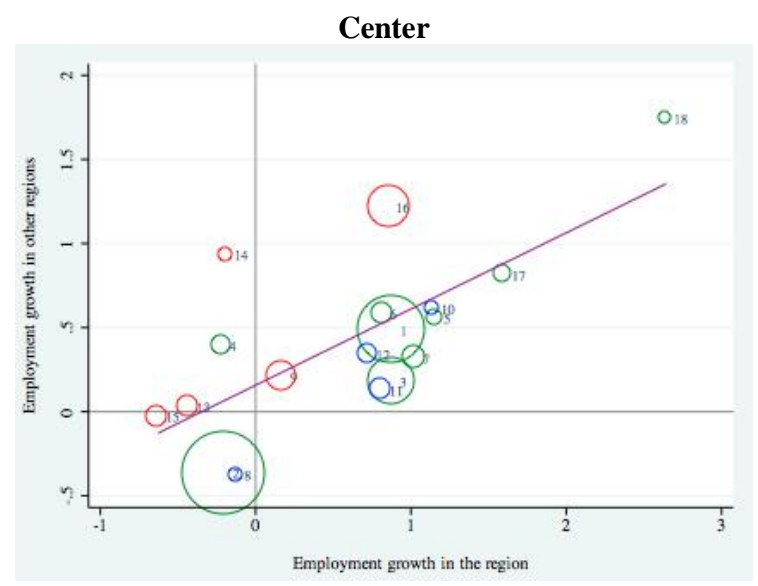

Low-technology intensity
Medium-low technology intensity
Medium-high technology intensity

1 Food, beverages and tobacco

2 Textiles

3 Apparel

4 Leather and footwear

5 Wood

6 Paper

7 Printing

8 Petroleum and coal products

9 Chemical industry

10 Plastics and rubber

11 Non-metallic mineral products

12 Primary metal manufacturing and metal products

13 Machinery and equipment

14 Computers and electronics

15 Electric apparatus

16 Transportation equipment

17 Furniture and mattresses

18 Other industries

*Marker sizes are based upon total employment in the region-sector.

Source: Author's calculations with data from the 1989 and 2009 Economic Censuses, INEGI.

Regarding the variable that summarizes market conditions (initial wage), Figure 6 presents the relationship between this variable and employment growth by sector-MA for the two different periods analyzed ( $\tau=5$ and $\tau=20$ ). The data exhibits the expected negative relation (higher wages create negative incentives for the location of industries in an MA). This relation appears to be more negative for $\tau=20$.

FIGURE 6. CORRELATION BETWEEN INITIAL WAGE AND EMPLOYMENT GROWTH IN THE INDUSTRY-MA
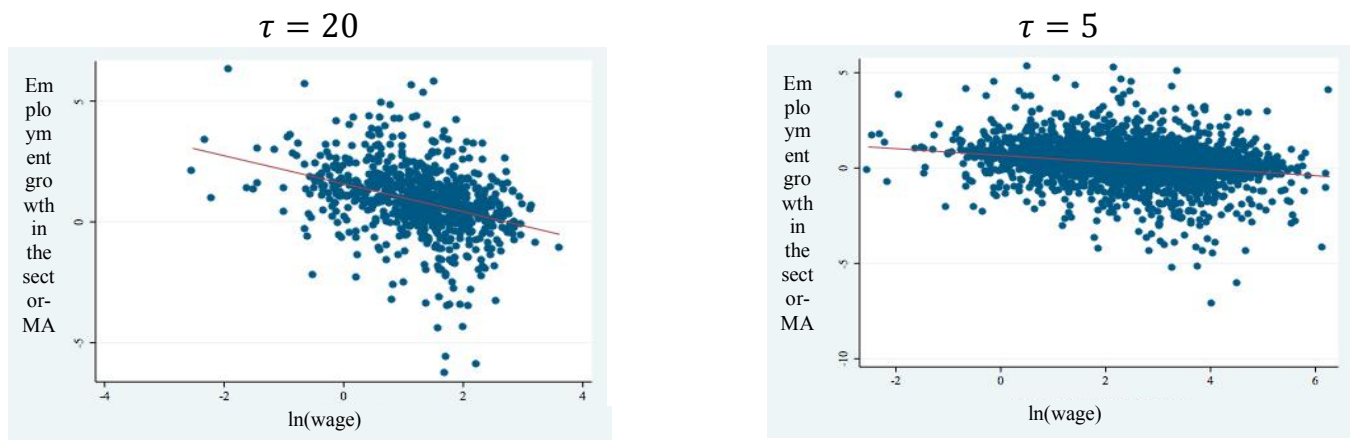

Source: Author's calculations with data from the 1989, 1994, 1999, 2004 and 2009 Economic Censuses, INEGI. 


\section{TABLE 2. DESCRIPTIVE STATISTICS OF INDEPENDENT VARIABLES}

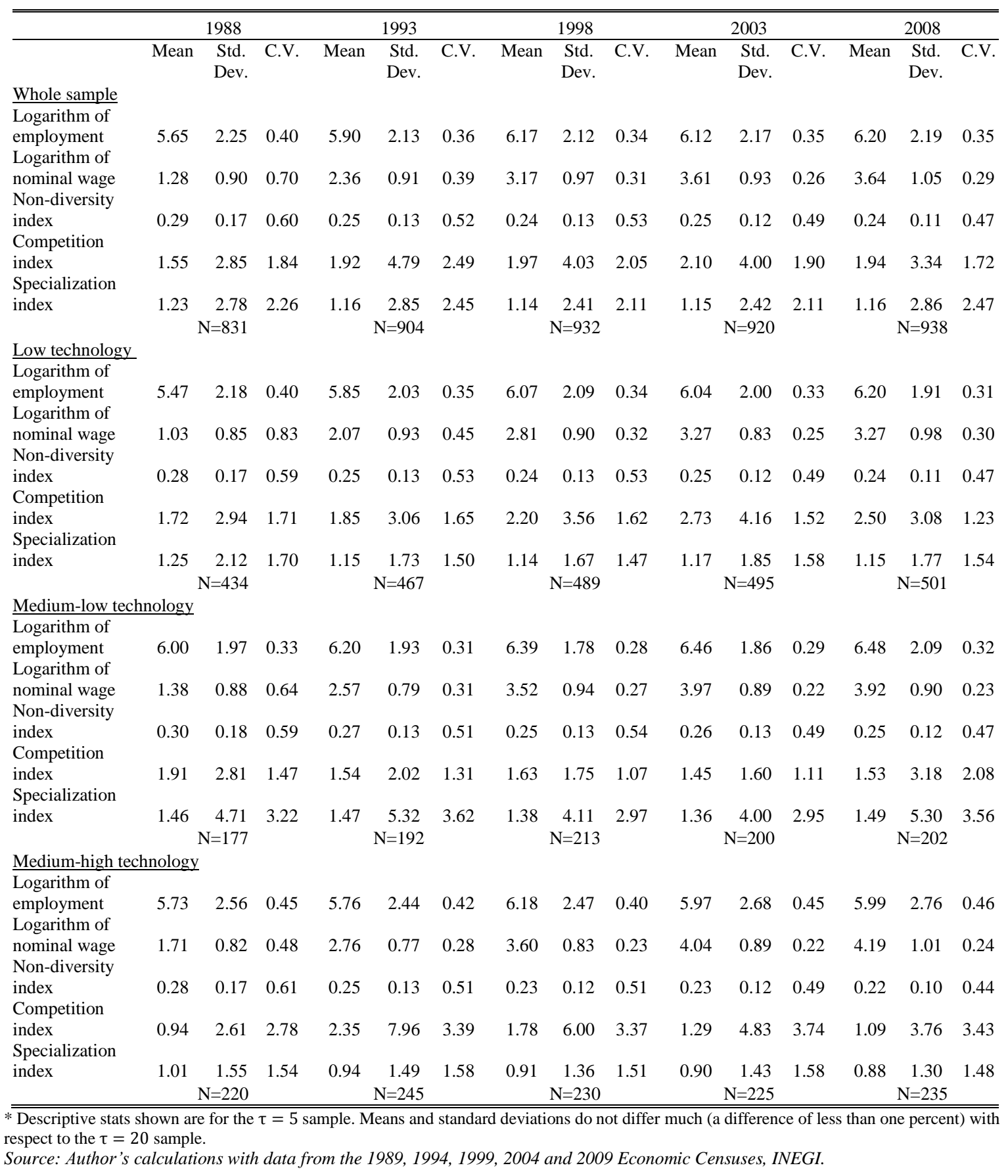


As Table 2 shows, the specialization index by technological intensity does not show much specialization (mean values close to unity), but standard deviations for each group indicate that there are MAs where industries are overrepresented, especially for medium-low technology industries. Considering this variable's relation to employment growth, as Figure 7 shows, the relation is not clear (probably because there is a great deal of low values) and if it exists, it appears to be negative, which is an unexpected pattern in the framework of MAR economies, although consistent with other studies such as Glaeser et al. (1992). The relation between employment growth and the non-diversity index (both the HHI and the Theil index) is also not clear and appears to have a sign contrary to what is expected in this literature (Figure 8).

FIGURE 7. CORRELATION BETWEEN THE SPECIALIZATION INDEX AND EMPLOYMENT GROWTH IN THE INDUSTRY-MA

$$
\tau=20 \quad \tau=5
$$
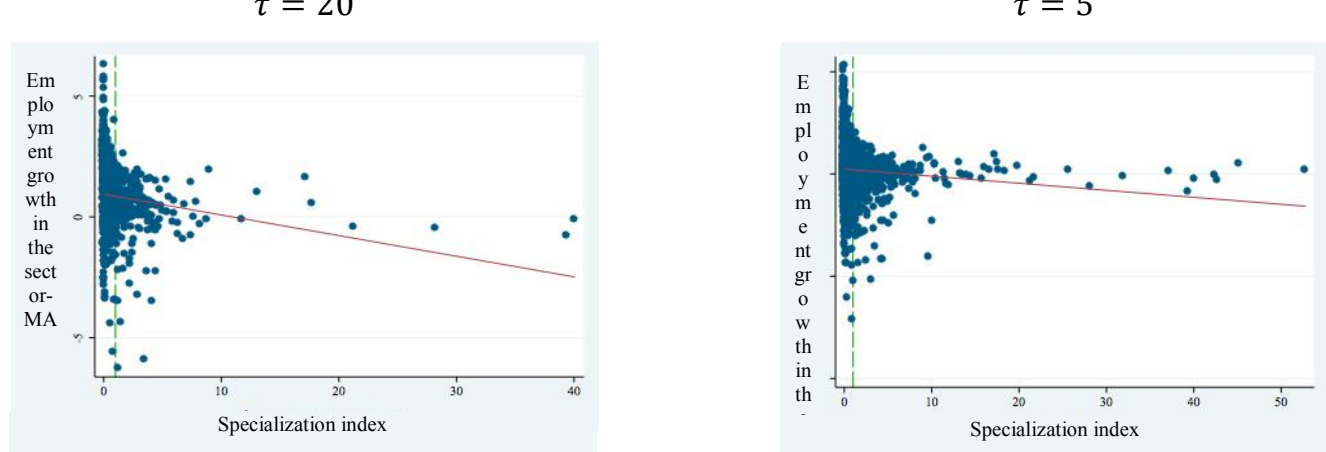

Source: Author's calculations with data from the 1989, 1994, 1999, 2004 and 2009 Economic Censuses, INEGI.

FIGURE 8. CORRELATION BETWEEN INITIAL NON-DIVERSITY AND EMPLOYMENT GROWTH IN THE INDUSTRY-MA
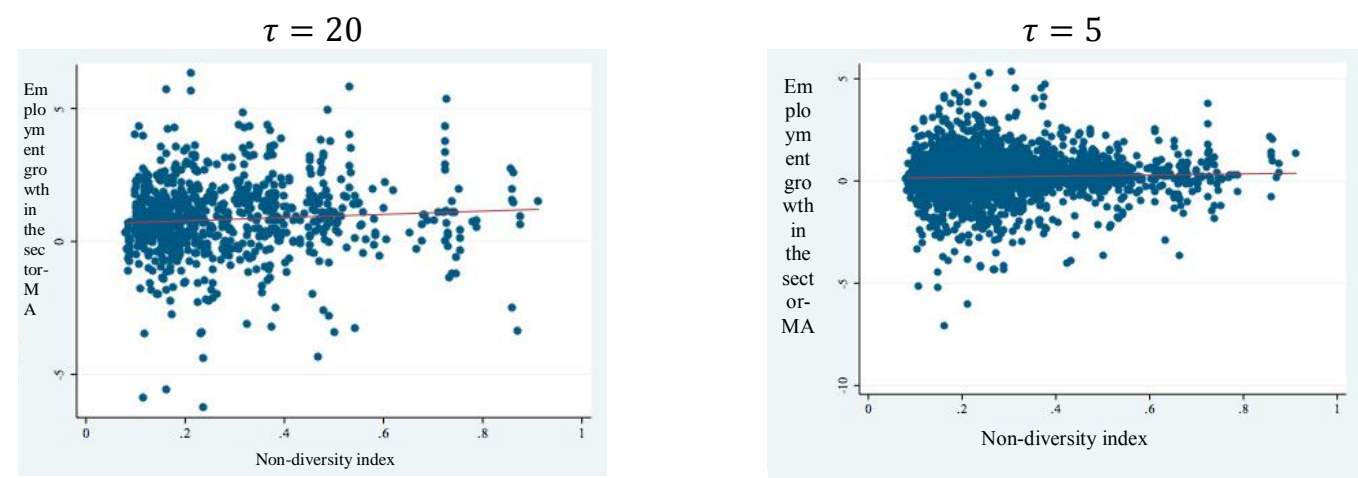

Source: Author's calculations with data from the 1989, 1994, 1999, 2004 and 2009 Economic Censuses, INEGI.

Finally, the competition index appears to have a positive linear relation with employment growth, although the slope is not very steep (mainly in the case of $\tau=5$ ). That is, initial 
competition seems to positively affect employment growth in an MA, which is consistent both with Jacobs and Porter economies, depending on other indicators (Figure 9).

FIGURE 9. CORRELATION BETWEEN INTITIAL COMPETITION AND EMPLOYMENT GROWTH IN THE INDUSTRY-MA

$$
\tau=20
$$

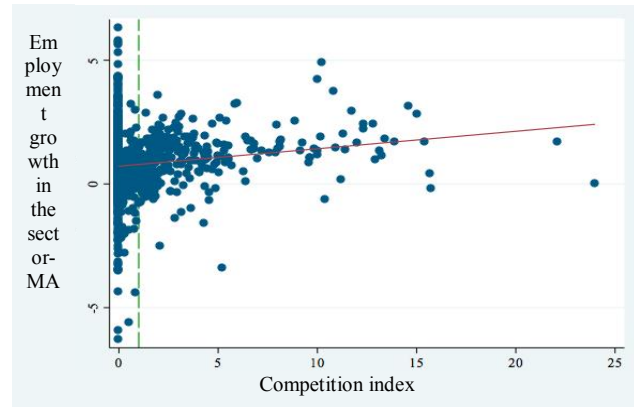

$\tau=5$

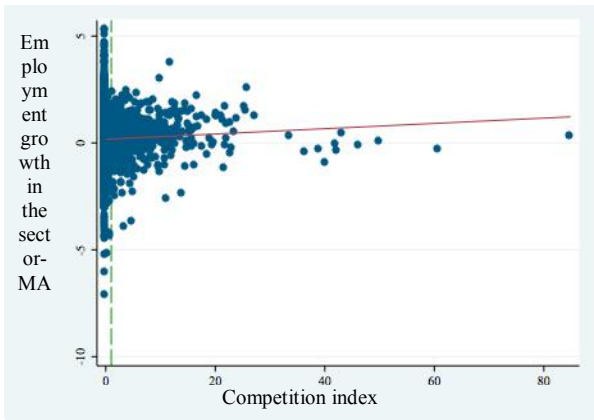

Source: Author's calculations with data from the 1989, 1994, 1999, 2004 and 2009 Economic Censuses, INEGI.

\section{Results}

\subsection{Results for $\tau=20$}

\subsubsection{Whole sample}

Table 3 shows the results for the whole sample, that is, without sectoral or technological intensity breakdowns. The results for the variables of interest (wages and agglomeration economies variables) are robust to the inclusion of regional effects, share of the MA in the maquiladora industry employment and MAs fixed effects. The F-test over fixed effects(E6) shows that they are jointly significant.

As expected, initial wages have a negative, though small, effect in employment growth for an MA-sector. Thus, a 10\% higher wage in 1988 reduces growth by 2.2 percentage points during the twenty-year period analyzed.

Regarding the variables associated with knowledge spillovers, the specialization index that indicates MAR or Porter economies is not significant in any specification while the competition variable is positive and significant, but low; if a sector increases its competition level against country average by $10 \%$, it will result in an increase of half a percentage point in employment growth in the period of analysis. Finally, the non-diversity variable is significant in all specifications. Therefore, in average, the externalities observed are consistent with Jacobs or urbanization economies. 
TABLE 3. RESULTS FOR $\tau=20$ (STANDARDIZED COEFFICIENTS) $^{16}$

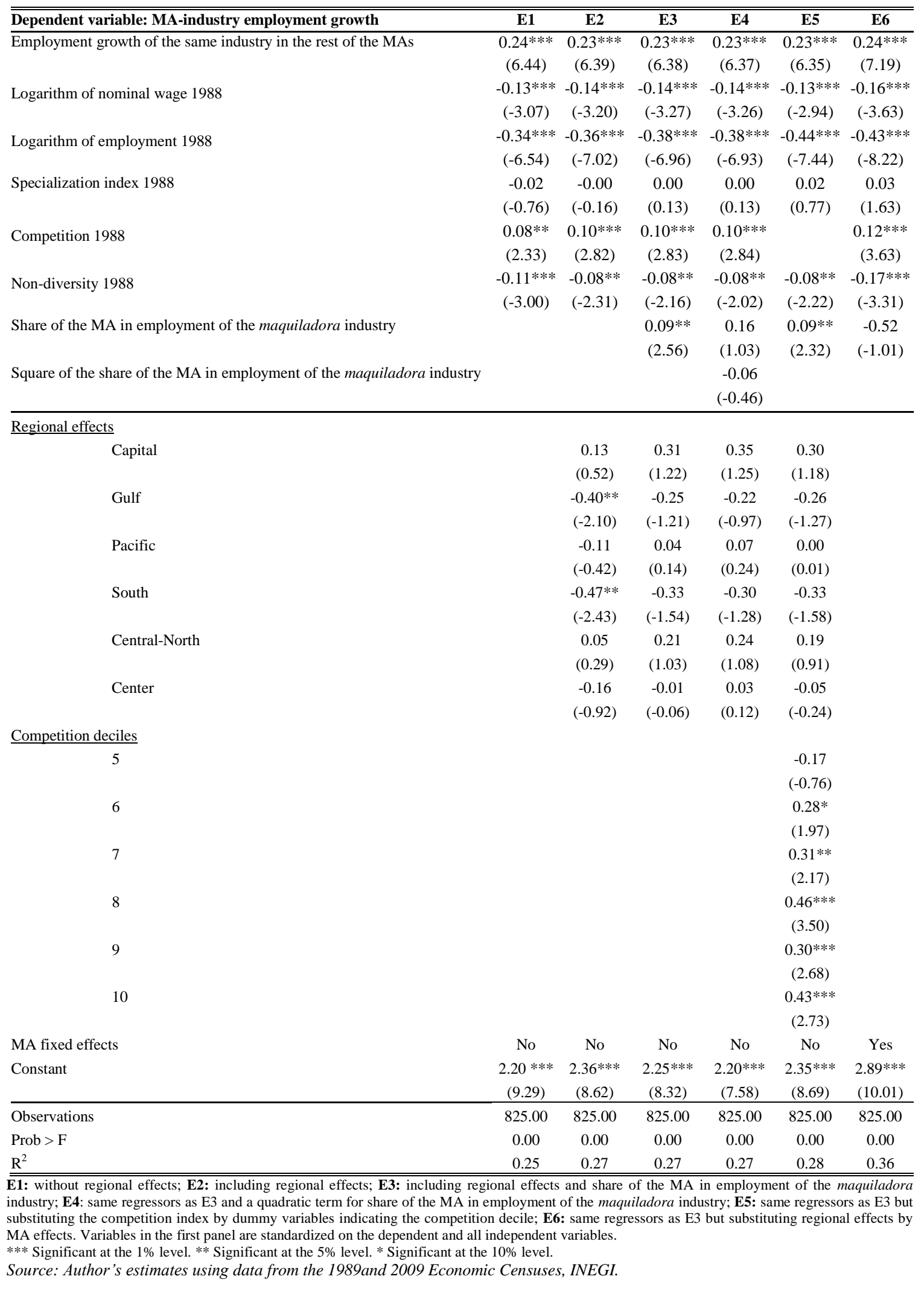

${ }^{16}$ Coefficients are standardized on both the dependent and independent variables. 
Analyzing whether market conditions (wages) or agglomeration economies (competition and diversity) have a greater impact on economic growth, the results indicate that urbanization economies are more important, since considered jointly, the standardized coefficients of these two variables are higher than initial wages, and as Table 2 shows, their coefficients of variation are equal or greater than that of the wages variable. This indicates that when growing (in terms of employment) in a region, industries give more valueto urbanization than wages. However, results are expected to differ by technological intensity groups.

Regarding the variable to control for maquiladora industry, the coefficient is positive and significant except when a quadratic term is included (E4) and when fixed effects for the 58 MA are included (E6). That is, the effect of the share of an MA in total maquiladora industry employment is absorbed by the particular characteristics of the MA. Additionally, results are consistent with the regional concentration of this industry (located mainly in the northern region) as once a control for the maquiladoraindustry is included, regional effects are no longer significant.

\section{Robustness checks}

- Measurement error in the competition variable:Due to confidentiality concerns, when in a municipality the number of firms is as small as to easily identify the firms included, INEGI does not report the number of firms. Therefore, the number of establishments for these cases is considered as cero. Thus, competition is underestimated. This measurement error should not be important since the "cero cases" are indeed of low competition. However, in order to ensure the robustness of the results, equation (4.1) was estimated including dummy variables for each decile of competition (column E5 of Table 3). Results indicate that employment growth rate between 1988 and 2008 increases with each decile of competition, which shows that results are robust.

- Endogeneity due to the use of initial values (1988): Even though econometric specifications in the framework of growth literature use as a control the initial value (see Durlauf, Johnson, \& Temple, 2005), in order to ensure exogeneity the dependent variable was changed for employment growth between 1993 and 2008, keeping the initial values for 1988. Results are similar to the ones presented in Table 3. 
- Non-diversity indicator:Considering that the inclusion of the non-diversity variable is related to inequality in the distribution of employment in other sectors, following studies such as Paci and Usai (2000) and Van Oort (2007), an inequality index is tested. Other papers use the Gini coefficient to account for non diversity. However, since the normalized Theil index ${ }^{17}$ has better properties (is decomposable), this indicator was used in order to assess the robustness of the results obtained using the HHI. As Figure 10 shows, the correlation between both variables is high (0.96). Therefore, results obtained using the Theil index are very similarto the ones obtained using the HHI.

Figure 10. CORRELATION BETWEEN THE THEIL INDEX AND THE HHI

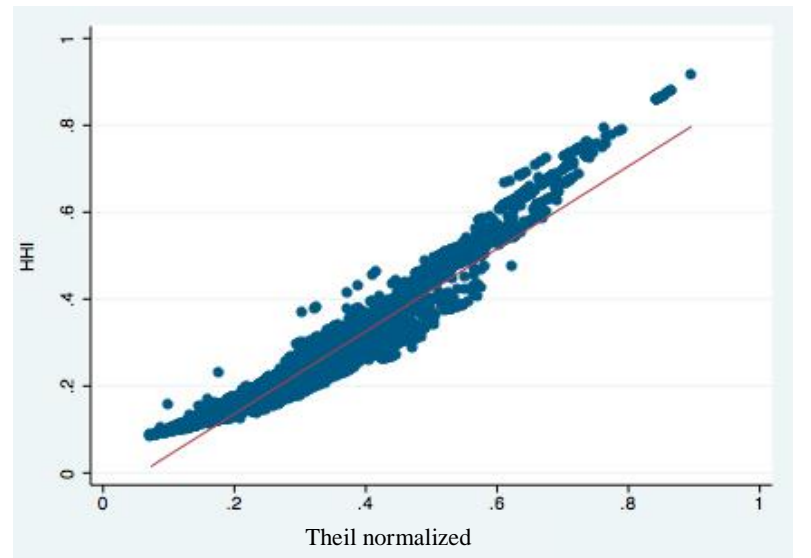

Source: Author's calculations with data from the 1989, 1994, 1999, 2004 and 2009 Economic Censuses, INEGI.

- Regional labor markets:In principle, the assumption of a national labor market should not be too restrictive since there were migration flows during this period within the country. ${ }^{18}$ In order to assess the validity of this assumption, firstly, regional wages were analyzed using the north as the basis. If the ratios of regional wages against the north did not change much during the period of analysis, the assumption of a national labor market, in which wages growth rates are the same, can be made. However, as Figure 11 shows, this is not the case, since the ratios have changed. In order to evaluate the effect of this assumption on the results, the 2008 wage was included as an independent variable with the purpose of controlling for unequal wage growth. The hypothesis

17 The normalized Theil index is given by:

$$
T_{i j, T-\tau}=\frac{1}{(I-1)} \frac{1}{\ln (I-1)} \sum_{k \neq i}^{I}\left(\frac{l_{k, j, t-\tau}}{\bar{l}}\right) \ln \left(\frac{l_{k, j, t-\tau}}{\bar{l}}\right)
$$

where $(I-1)$ is the number of sectors different from the one analyzed. That is, if in an MA 18 sectors are present, $(I-$ $1)=17$.

18 According to Soloaga, Lara, and Wendelspiess (2010) between 1975 and 2000 approximately 800,000 people migrated on an annual basis between the different states of Mexico. Between 2000 and 2005, this figure was 530,000 . 
that coefficients were equal to the ones presented in Table 3, could not be rejected in any specification. $^{19}$

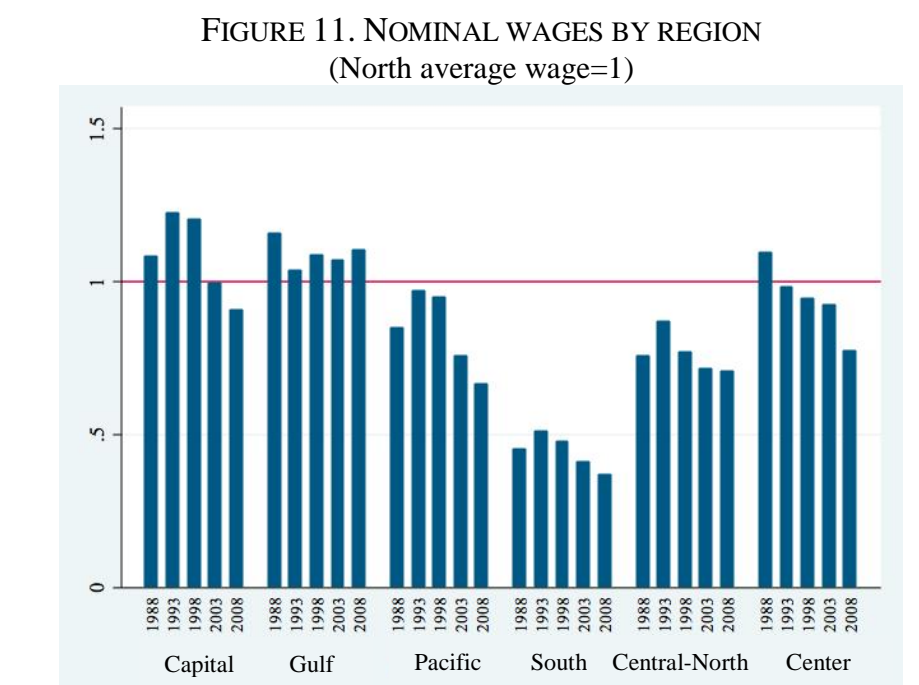

Source: Author's calculations with data from the 1989, 1994, 1999, 2004 and 2009 Economic Censuses, INEGI.

- Sectoral labor markets: It is important to evaluate the possibility of sectoral labor markets, which is feasible due to the sectoral variability in average wages growth (see Figure 12). Including sectoral interactions with the wages variable in equation 4.1, the results indicate that the effect of initial wages differs by sector and, furthermore, in some medium-high technology sectors these coefficients are positive indicating that some industries tend to grow in locations with higher initial wages. Therefore, it is important to estimate the equation by technological intensity in order to assess whether the effects of market conditions and agglomeration variables, differ across groups.

\footnotetext{
${ }^{19}$ Furthermore, it is not possible to reject the hypothesis that, in absolute terms, the coefficient of initial wages and final wages is the same, which indicates that the wage variable can be included in the equation in terms of growth rates.
} 
FIGURE 12. SECTORAL AVERAGE WAGE GROWTH 1988-2008
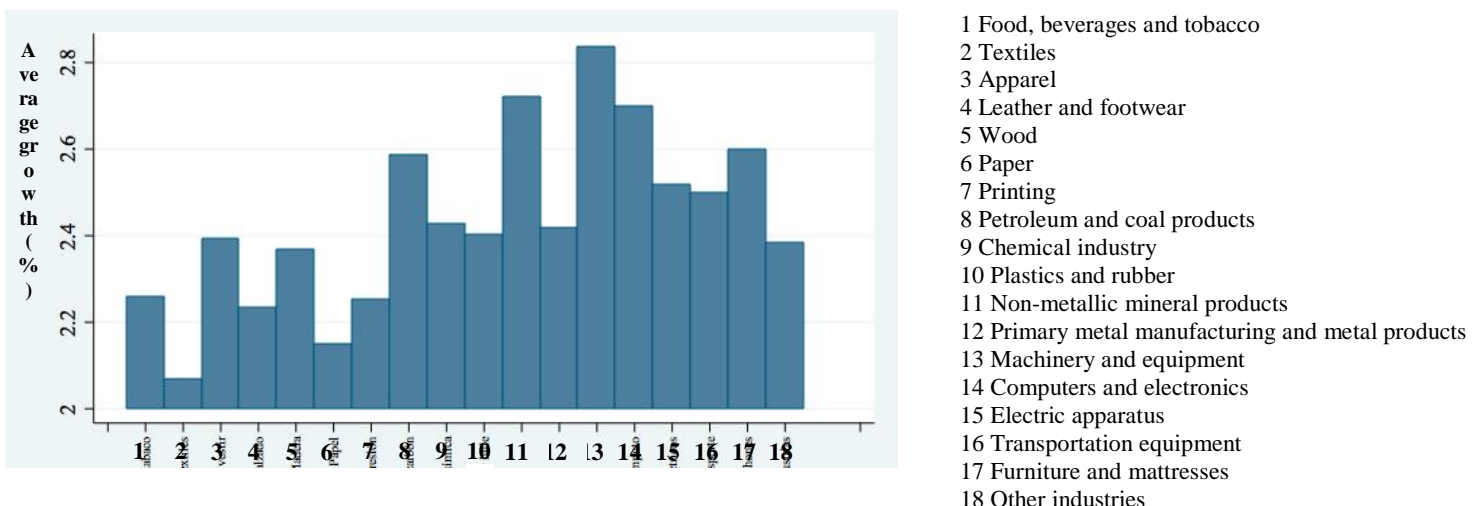

Source: Author's calculations with data from the 1989and 2009 Economic Censuses, INEGI.

\section{$\underline{5.1 .2}$ Technological intensity breakdown}

As Table 4 shows, results are statistically different for each technological intensity group, at the one percent significance level. It is important to highlight the following results: (1) Wages are only significant in the case of low technology. This group also exhibits Jacobs economies (competition and non-diversity) and, due to the same reasons mentioned in the previous section, the most important factor are these externalities. (2) In the case of medium-low technology, agglomeration externalities are the determinant of employment growth and a combination of Jacobs and Porter economies is present (competition, non-diversity and specialization are significant). (3) For medium-high technology industries, neither market conditions nor agglomeration variables are significant; only controls and MA effects are statistically different from zero. These results indicate that these industries consider other kinds of factors when they decide whether to increase their presence in an MA.

In general, results show that, as expected, low-technology industries are more sensitive to initial wages and agglomeration factors operate differently, depending on technological intensity.

Sectoral regressions ${ }^{20}$ were performed, in order to assess the robustness of these results as well as the validity of Glaeser et al. (1992) assumption that agglomeration economies have the same effect regardless of the economic sector. In principle, this assumption is rejected as in a test on the coefficients for 18 sectors, the hypothesis that coefficients are equal across sectors is

\footnotetext{
${ }^{20}$ Results are not shown here but are available upon request.
} 
rejected. Results are consistent with Table 4, as low-technology sectors, such as food and beverages and textiles, are more sensitive to initial wages, while for higher technology sectors wages effects are negligible.

TABLE 4. SUR ESTIMATES BY TECHNOLOGICAL INTENSITY, $\tau=20$ (STANDARDIZED COEFFICIENTS)

\begin{tabular}{|c|c|c|c|}
\hline Dependent variable: MA-industry employment growth & Low & Medium-low & Medium-high \\
\hline $\begin{array}{l}\text { Employment growth of the same industry in the rest of the } \\
\text { MAs }\end{array}$ & $\begin{array}{l}0.21 * * * \\
(5.45)\end{array}$ & $\begin{array}{l}0.43^{* * *} \\
(6.33)\end{array}$ & $\begin{array}{l}0.23 * * * \\
(3.49)\end{array}$ \\
\hline Logarithm of nominal wage 1988 & $\begin{array}{l}-0.10^{*} \\
(-1.74)\end{array}$ & $\begin{array}{r}-0.13 \\
(-1.29)\end{array}$ & $\begin{array}{r}-0.03 \\
(-0.27)\end{array}$ \\
\hline Logarithm of employment 1988 & $\begin{array}{l}-0.73 * * * \\
(-9.99)\end{array}$ & $\begin{array}{l}-0.77 * * * \\
(-5.39)\end{array}$ & $\begin{array}{l}-0.52 * * \\
(-2.44)\end{array}$ \\
\hline Specialization index of the industry 1988 & $\begin{array}{r}0.04 \\
(1.24)\end{array}$ & $\begin{array}{l}0.20^{* * * *} \\
(2.99)\end{array}$ & $\begin{array}{r}0.11 \\
(0.77)\end{array}$ \\
\hline Non-diversity 1988 & $\begin{array}{l}-0.23 * * * \\
(-4.36)\end{array}$ & $\begin{array}{l}-0.29 * * \\
(-2.15)\end{array}$ & $\begin{array}{r}-0.23 \\
(-0.83)\end{array}$ \\
\hline Share of the MA in employment of the maquiladora industry & $\begin{array}{l}-1.30 * \\
(-1.66) \\
\end{array}$ & $\begin{array}{r}-0.35 \\
(-0.32) \\
\end{array}$ & $\begin{array}{r}0.46 \\
(1.23) \\
\end{array}$ \\
\hline \multicolumn{4}{|l|}{ Competition deciles } \\
\hline 5 & $\begin{array}{r}-0.52 \\
(-1.57)\end{array}$ & $\begin{array}{r}-0.39 \\
(-1.27)\end{array}$ & $\begin{array}{r}-0.01 \\
(-0.03)\end{array}$ \\
\hline 6 & $\begin{array}{r}0.30 \\
(1.58)\end{array}$ & $\begin{array}{l}0.91^{* * *} \\
(3.46)\end{array}$ & $\begin{array}{r}-0.23 \\
(-0.43)\end{array}$ \\
\hline 7 & $\begin{array}{l}0.42 * * \\
(2.24)\end{array}$ & $\begin{array}{l}0.51 * * * \\
(2.66)\end{array}$ & $\begin{array}{r}0.13 \\
(0.30)\end{array}$ \\
\hline 8 & $\begin{array}{l}0.29 * \\
(1.84)\end{array}$ & $\begin{array}{l}0.88^{* * *} \\
(4.07)\end{array}$ & $\begin{array}{r}0.53 \\
(1.10)\end{array}$ \\
\hline 9 & $\begin{array}{r}0.01 \\
(0.10)\end{array}$ & $\begin{array}{l}0.98^{* * * *} \\
(4.34)\end{array}$ & $\begin{array}{r}-0.24 \\
(-0.53)\end{array}$ \\
\hline 10 & $\begin{array}{r}0.21 \\
(1.36)\end{array}$ & $\begin{array}{l}1.17 * * * \\
(5.15)\end{array}$ & $\begin{array}{r}0.68 \\
(1.46)\end{array}$ \\
\hline MA fixed effects & Yes & Yes & Yes \\
\hline Constant & $\begin{array}{l}4.05 * * * \\
(12.28) \\
\end{array}$ & $\begin{array}{l}2.86^{* * * *} \\
(7.31) \\
\end{array}$ & $\begin{array}{l}2.98^{* * * *} \\
(3.88) \\
\end{array}$ \\
\hline $\mathrm{N}$ & 433.00 & 179.00 & 213.00 \\
\hline $\mathrm{p}$ & 0.00 & 0.00 & 0.08 \\
\hline $\mathrm{R}^{2}$ & 0.57 & 0.64 & 0.38 \\
\hline
\end{tabular}




\section{$\underline{\text { 5.1.3 Fixed effects analysis }}$}

As Tables 3 and 4 show, even after controlling for market conditions (wages) and agglomeration economies (specialization, non diversity and competition), there still are some regional characteristics (relative advantages or disadvantages), captured by dummies, which affect regional growth. The importance of analyzing these factors stems from their relation with regional infrastructure: a factor that canbe corrected or improved (in the case of disadvantages) through public policy.

Figure 13 shows regional fixed effects. In the case of low-technology sectors, as the figure depicts, there are no regions with a relative disadvantage. ${ }^{21}$ This makes sense, considering that this kind of industry tend to move easily across regions. In this group of industries a clear regional location pattern is observed, as relative advantages are concentrated in the central region. In the case of the medium-low technology group, regional effects are not significant, indicating that there are neitherrelative advantages nor relative disadvantages. Finally, mediumhigh technology industries also show a clear regional pattern with relative disadvantages localized in the southern area of the country. In fact, the south is the region with the highest level of disadvantage.

FIGURE 13. REGIONAL FIXED EFFECTS

A) Low technology

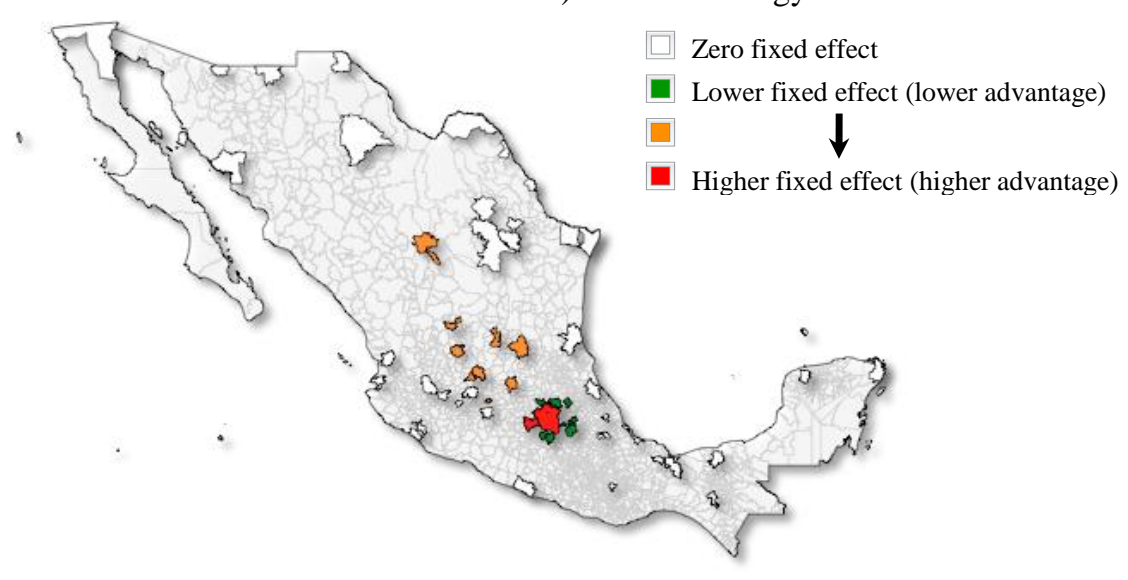

\footnotetext{
${ }^{21}$ The basis is the northern region but the null hypothesis that there are no differences against that region can't be rejected for any other region. Thus, this test can be interpreted as advantage or disadvantage against other regions.
} 
B) Medium-high technology

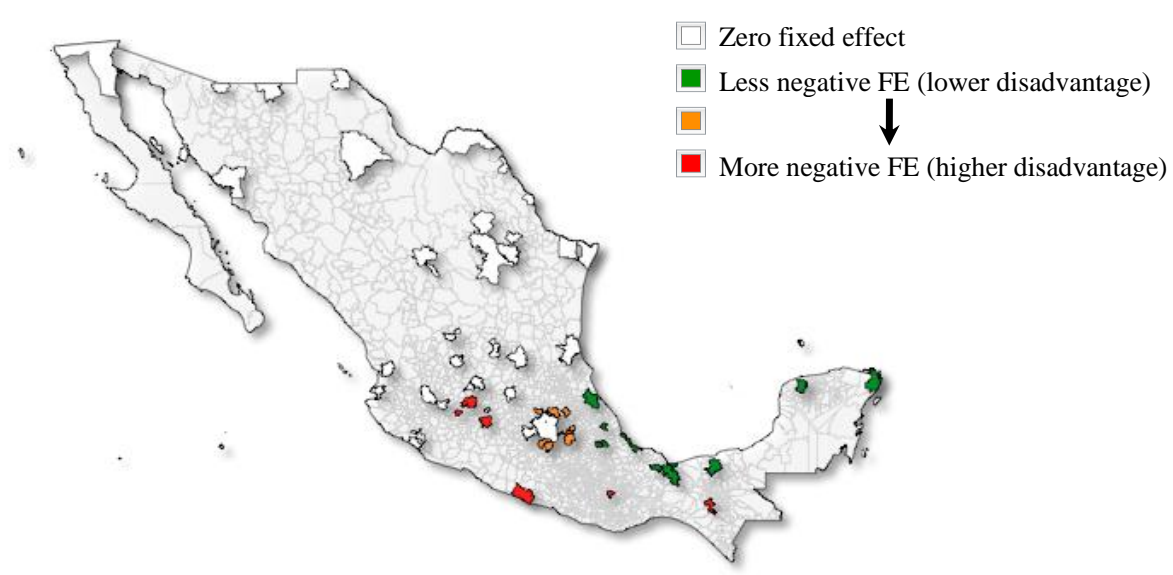

Source: Author's estimates with data from the 1989 and 2009 Economic Censuses using the results from Table 4.

The only case in which an advantage in low-technology is accompanied by a disadvantage in medium-high technology sectors is the center, a result that reflects the changes experienced by this region in the last twenty years.

Table 5 shows the analysis of how much the non-diversity index should change in regions that exhibit relative disadvantages for employment growth in medium-high technology sectors ${ }^{22}$ in order to compensate these negative fixed effects and attract these kinds of industries. For example, the south should reduce its index (become more diverse) in 0.14 to compensate its disadvantage against the Center (the region with the second higher disadvantage); however, that kind of change would imply to achieve a level of diversity comparable with the north, which does not appear to be plausible because that is the leader region, as mentioned before. Thus, there is no agglomeration variable in the equation capable of compensating these relative disadvantages.

The analysis of how the regional disadvantages by technological intensity group correlate at the MA level shows that firstly the correlation between the low-technology and medium-low technology groups is 0.46 . However, the correlation between either of these two groups and the medium-high technology group is approximately 0.29. These figures show that relative advantages or disadvantages are more similar in the case of the two lower technological intensity groups.

\footnotetext{
${ }^{22}$ The non-diversity index was selected because, though it is not significant in the specification shown in Table 4 , it is the only significant agglomeration variable in a specification including regional effects.
} 
TABLE 5. REQUIRED CHANGE IN THE NON-DIVERSITY INDEX IN ORDER TO COMPENSATE RELATIVE DISADVANTAGES IN MEDIUM-HIGH TECHNOLOGY SECTORS

\begin{tabular}{|c|c|c|c|c|}
\hline & & \multicolumn{3}{|c|}{$\begin{array}{l}\text { Change in the non-diversity index in order to eliminate disadvantages with } \\
\text { respect to: }\end{array}$} \\
\hline & $\begin{array}{l}\text { Non-diversity index } \\
\text { mean }\end{array}$ & Center & Gulf & Rest \\
\hline South & 0.39 & -0.14 & -0.17 & -0.68 \\
\hline Center & 0.24 & & -0.03 & -0.55 \\
\hline Gulf & 0.40 & & & -0.52 \\
\hline North & 0.25 & & & \\
\hline Capital & 0.11 & & & \\
\hline Pacific & 0.35 & & & \\
\hline Central-North & 0.28 & & & \\
\hline
\end{tabular}

Source: Author's calculations using estimates similar to the ones presented in Table 4, but including regional effects instead of MA effects. These results are available upon request.

Figure 14 shows a summary of the fixed effects for MAs that exhibit advantages or disadvantages in more than one kind of industry. In this case, the basis is Aguascalientes, but since the difference against this MA is not statistically significant for most of the other MAs results can be interpreted as against the rest. Three MAs have disadvantages for all technological intensity groups: Tulancingo, Rioverde-Cd. Fernandez, and Veracruz. Leon, Toluca and Coatzacoalcos show relative advantages for both low-technology and medium-low technology industries. Finally, only Reynosa-Rio Bravo exhibits a relative advantage for growth in mediumlow and medium-high technology groups.

FIGURE 14. SUMMARY OF MA FIXED EFFECTS

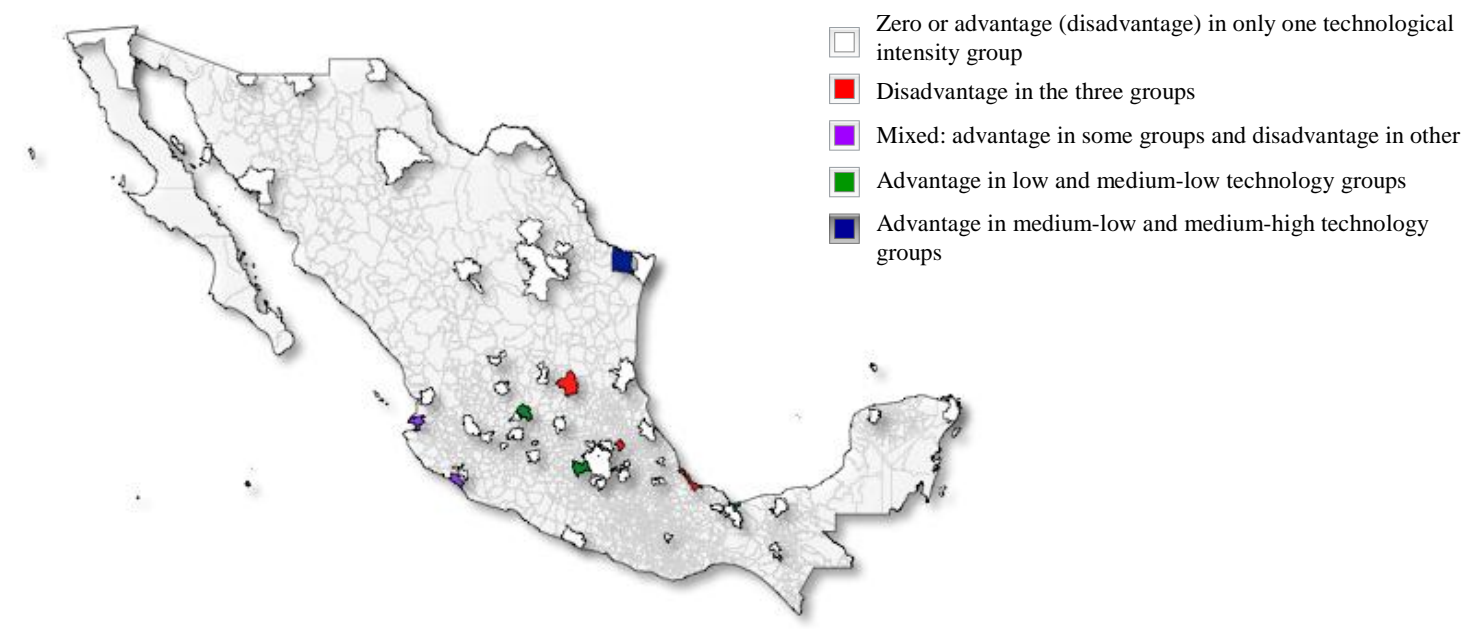

Source: Author's estimates with data from the 1989 and 2009 Economic Censuses usingresults from Table 4. 


\subsection{Results for $\tau=5$}

\subsubsection{Whole sample}

The same analysis was performed for $\tau=5$ but due to the panel structure of the data time effects were included and real wages (2003 prices) were used. As Table 6 shows, results for control variables (logarithm of initial employment, growth in the rest of the MAs) don't change much against the results from Table 3. However, there are changes in the variables of interest; for example, the coefficient of initial wages is still significant, although its magnitude reduces mainly because the variable is in real terms now. ${ }^{23}$ Considering the F-test over MA fixed effects, the hypothesis that all coefficients are zero is rejected (column E6 in Table 6).

Regarding agglomeration variables, the conclusion from these results is that Porter externalities are observed (specialization and competition are significant). ${ }^{24}$

Considering which factor has greater effects on industrial growth in an MA (market conditions or agglomeration economies), in this case the conclusion would be different from the one presented in section 5.1 .1 as it is necessary to consider how the different independent variables have changed over time. In this case, as Figure 15 shows, real wages are the variable that has changed most in terms of its mean and distribution. ${ }^{25}$ Therefore, they are the main determinant of short-term industrial growth.

An interesting and robust result across the different specifications is that time effects show a " $v$ " pattern that reaches its minimum in 2003 and then returns to a value similar to the one of 1998. These parameters could be related to the macroeconomic environment. However, results differ across technological intensity groups and sectors (Table 7), which could indicate that macroeconomic factors do not affect all groups in the same manner.

\footnotetext{
${ }^{23}$ If nominal wages are used, the standardized coefficient changes from -0.05 in column E1 of Table 6 to -0.09 .

${ }^{24}$ As a robustness check, and in order to analyze the effect of the initial period once we control for other realizations of these same variables, the equation was estimated using the dynamic panel methodology developed by Blundell and Bond (1998), and a lag structure similar to the one used by Henderson (1997). Results indicate that controlling for other realizations of the same variables, wage remains as the variable that has more dynamic effects, while in terms of agglomeration economies, the data is consistent with Jacobs economies, similar to what was obtained for $\tau=20$.

${ }^{25}$ The non-diversity variable also exhibits change in its distribution, but as Table 6 shows it is not significant in the specification that includes MA fixed effects, which are jointly significant.
} 
TABLE 6. RESULTS FOR $\tau=5$ (STANDARDIZED COEFFICIENTS)

\begin{tabular}{|c|c|c|c|c|c|c|}
\hline & E1 & E2 & E3 & E4 & E5 & E6 \\
\hline $\begin{array}{l}\text { Employment growth of the same industry in the } \\
\text { rest of the MAs }\end{array}$ & $\begin{array}{c}0.25 * * * \\
(9.27)\end{array}$ & $\begin{array}{c}0.25 * * * \\
(9.13)\end{array}$ & $\begin{array}{c}0.25 * * * \\
(9.14)\end{array}$ & $\begin{array}{c}0.25 * * * \\
(9.14)\end{array}$ & $\begin{array}{c}0.25^{* * * *} \\
(9.15)\end{array}$ & $\begin{array}{l}0.25 * * * \\
(-11.70)\end{array}$ \\
\hline Logarithm of nominal wage in $t-5$ & $\begin{array}{c}-0.05 * * \\
(-2.32)\end{array}$ & $\begin{array}{l}-0.06 * * \\
(-2.54)\end{array}$ & $\begin{array}{l}-0.06 * * \\
(-2.54)\end{array}$ & $\begin{array}{c}-0.06 * * \\
(-2.53)\end{array}$ & $\begin{array}{l}-0.04 \\
(-1.44)\end{array}$ & $\begin{array}{c}-0.06 * * * \\
(-2.46)\end{array}$ \\
\hline Logarithm of employment in $t-5$ & $\begin{array}{l}-0.20 * * * \\
(-7.40)\end{array}$ & $\begin{array}{l}-0.22 * * * \\
(-7.63)\end{array}$ & $\begin{array}{l}-0.23 * * * \\
(-7.52)\end{array}$ & $\begin{array}{c}-0.23 * * * \\
(-7.49)\end{array}$ & $\begin{array}{c}-0.30 * * * \\
(-9.19)\end{array}$ & $\begin{array}{r}-0.38 * * * \\
(-10.96)\end{array}$ \\
\hline Specialization index in $t-5$ & $\begin{array}{c}-0.02 \\
(-1.13)\end{array}$ & $\begin{array}{l}-0.01 \\
(-0.62)\end{array}$ & $\begin{array}{l}-0.01 \\
(-0.38)\end{array}$ & $\begin{array}{l}-0.01 \\
(-0.35)\end{array}$ & $\begin{array}{c}0.00 \\
(0.19)\end{array}$ & $\begin{array}{l}0.04 * * \\
(-3.10)\end{array}$ \\
\hline Competition in $t-5$ & 0.01 & 0.02 & 0.02 & 0.02 & & \\
\hline Non-diversity in $t-5$ & $\begin{array}{c}(0.84) \\
-0.08 * * * \\
(-4.37)\end{array}$ & $\begin{array}{c}(1.04) \\
-0.07 * * * \\
(-3.64)\end{array}$ & $\begin{array}{c}(1.09) \\
-0.07 * * * \\
(-3.73)\end{array}$ & $\begin{array}{c}(1.13) \\
-0.06 * * * \\
(-3.61)\end{array}$ & $\begin{array}{c}-0.06 * * * \\
(-3.82)\end{array}$ & $\begin{array}{l}-0.03 \\
(-0.84)\end{array}$ \\
\hline $\begin{array}{l}\text { Share of the MA in employment of the } \\
\text { maquiladora industry in } t-5\end{array}$ & & & $\begin{array}{c}0.06 * * * \\
(3.46)\end{array}$ & $\begin{array}{l}0.14 * * \\
(2.26)\end{array}$ & $\begin{array}{c}0.16^{* * *} \\
(2.56)\end{array}$ & $\begin{array}{l}-0.07 \\
(-0.61)\end{array}$ \\
\hline $\begin{array}{l}\text { Square of the share of the MA in employment of } \\
\text { the maquiladora industry in } t-5\end{array}$ & & & & $\begin{array}{c}-0.07 \\
(-1.41) \\
\end{array}$ & $\begin{array}{l}-0.09^{*} \\
(-1.74)\end{array}$ & \\
\hline Regional effects & & & & & & \\
\hline Capital & & $\begin{array}{c}0.10 \\
(1.58)\end{array}$ & $\begin{array}{l}0.17 * * \\
(2.52)\end{array}$ & $\begin{array}{c}0.20 * * \\
(2.63)\end{array}$ & $\begin{array}{c}0.20 * * * \\
(2.70)\end{array}$ & \\
\hline Gulf & & $\begin{array}{l}-0.13 * * \\
(-2.23)\end{array}$ & $\begin{array}{l}-0.07 \\
(-1.17)\end{array}$ & $\begin{array}{l}-0.05 \\
(-0.70)\end{array}$ & $\begin{array}{l}-0.05 \\
(-0.80)\end{array}$ & \\
\hline Pacific & & $\begin{array}{l}-0.07 \\
(-0.87)\end{array}$ & $\begin{array}{c}-0.01 \\
(-0.14)\end{array}$ & $\begin{array}{c}0.01 \\
(0.13)\end{array}$ & $\begin{array}{l}-0.00 \\
(-0.02)\end{array}$ & \\
\hline South & & $\begin{array}{c}-0.12 * * \\
(-2.22)\end{array}$ & $\begin{array}{c}-0.06 \\
(-1.09)\end{array}$ & $\begin{array}{c}-0.04 \\
(-0.61)\end{array}$ & $\begin{array}{c}-0.05 \\
(-0.78)\end{array}$ & \\
\hline Central-North & & $\begin{array}{c}0.02 \\
(0.24)\end{array}$ & $\begin{array}{l}0.08 \\
(1.11)\end{array}$ & $\begin{array}{c}0.10 \\
(1.38)\end{array}$ & $\begin{array}{c}0.09 \\
(1.20)\end{array}$ & \\
\hline Center & & $\begin{array}{l}-0.05 \\
(-0.96)\end{array}$ & $\begin{array}{c}0.01 \\
(0.15)\end{array}$ & $\begin{array}{c}0.04 \\
(0.56)\end{array}$ & $\begin{array}{c}0.03 \\
(0.47)\end{array}$ & \\
\hline Time effects & & & & & & \\
\hline 1998 & $\begin{array}{c}-0.15^{* * * *} \\
(-3.09)\end{array}$ & $\begin{array}{c}-0.14 * * * \\
(-2.90)\end{array}$ & $\begin{array}{c}-0.13 * * * \\
(-2.81)\end{array}$ & $\begin{array}{c}-0.13 * * * \\
(-2.82)\end{array}$ & $\begin{array}{c}-0.15 * * * \\
(-3.13)\end{array}$ & $\begin{array}{c}-0.12 * * * * \\
(-2.90)\end{array}$ \\
\hline 2003 & $\begin{array}{c}-0.34 * * * \\
(-6.60)\end{array}$ & $\begin{array}{c}-0.33 * * * \\
(-6.46)\end{array}$ & $\begin{array}{c}-0.32 * * * \\
(-6.24)\end{array}$ & $\begin{array}{c}-0.32 * * * \\
(-6.21)\end{array}$ & $\begin{array}{c}-0.33 * * * \\
(-6.17)\end{array}$ & $\begin{array}{c}-0.28 * * * \\
(-6.31)\end{array}$ \\
\hline 2008 & $\begin{array}{c}-0.15 * * * \\
(-3.36)\end{array}$ & $\begin{array}{c}-0.14 * * * \\
(-3.10)\end{array}$ & $\begin{array}{c}-0.13 * * * \\
(-2.85)\end{array}$ & $\begin{array}{c}-0.13 * * * \\
(-2.85)\end{array}$ & $\begin{array}{c}-0.15 * * * \\
(-3.04)\end{array}$ & $\begin{array}{l}-0.11 * * * \\
(-2.68)\end{array}$ \\
\hline $\begin{array}{l}\text { Competition deciles } \\
4\end{array}$ & & & & & $\begin{array}{c}0.05 \\
(0.58)\end{array}$ & $\begin{array}{c}0.05 \\
(0.61)\end{array}$ \\
\hline 5 & & & & & $\begin{array}{l}0.18 * * * \\
(3.33)\end{array}$ & $\begin{array}{l}0.17 * * * \\
(2.65)\end{array}$ \\
\hline 6 & & & & & $\begin{array}{l}0.22 * * * \\
(4.42)\end{array}$ & $\begin{array}{c}0.20 * * * \\
(3.65)\end{array}$ \\
\hline 7 & & & & & $\begin{array}{l}0.22 * * * \\
(6.32)\end{array}$ & $\begin{array}{l}0.22 * * * \\
(4.30)\end{array}$ \\
\hline 8 & & & & & $\begin{array}{c}0.22 * * * \\
(5.19)\end{array}$ & $\begin{array}{c}0.22 * * * \\
(4.85)\end{array}$ \\
\hline 9 & & & & & $\begin{array}{l}0.19 * * * \\
(4.28)\end{array}$ & $\begin{array}{l}0.19 * * * \\
(3.84)\end{array}$ \\
\hline 10 & & & & & $\begin{array}{l}0.15 * * * \\
(3.19)\end{array}$ & $\begin{array}{l}0.16 * * * \\
(2.93)\end{array}$ \\
\hline MA fixed effects & No & No & No & No & No & Yes \\
\hline Constant & $\begin{array}{c}0.86 * * * \\
(9.15)\end{array}$ & $\begin{array}{c}0.90 * * * \\
(9.16)\end{array}$ & $\begin{array}{c}0.87 * * * * \\
(8.90)\end{array}$ & $\begin{array}{c}0.84 * * * \\
(8.71)\end{array}$ & $\begin{array}{c}0.93 * * * \\
(9.63)\end{array}$ & $\begin{array}{c}1.19 * * * \\
(9.24)\end{array}$ \\
\hline $\mathrm{N}$ & 3587 & 3587 & 3587 & 3587 & 3587 & 3587 \\
\hline $\mathrm{p}$ & 0.00 & 0.00 & 0.00 & 0.00 & 0.00 & 0.00 \\
\hline $\mathrm{R}^{2}$ & 0.16 & 0.16 & 0.17 & 0.17 & 0.18 & 0.20 \\
\hline
\end{tabular}

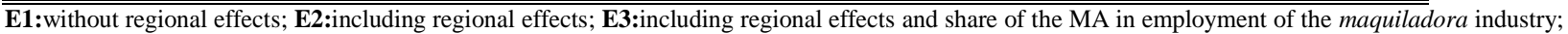
E4: same regressors as E3 and a quadratic term for share of the MA in employment of the maquiladora industry; E5: same regressors as E3 but substituting the competition index by dummy variables indicating the competition decile; E6:same regressors as E5 but substituting regional effects by MA effects.

Variables in the first panel are standardized on the dependent and all independent variables.

*** Significant at the $1 \%$ level. ** Significant at the 5\% level. *Significant at the $10 \%$ level.

Source: Author's estimates using data from the 1989, 1994, 1999, 2004 and 2009 Economic Censuses, INEGI. 
FIGURE 15. KERNEL DENSITIES OF INDEPENDENT VARIABLES

Logarithm ofthe real wage

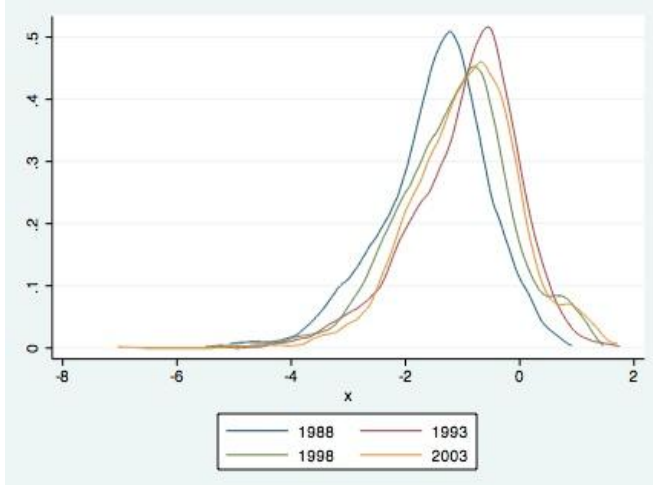

Competition index

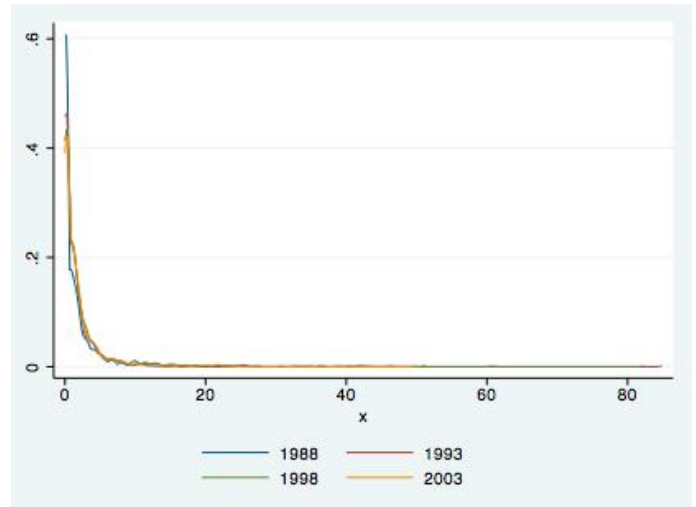

Share of the MA in the maquiladora industry

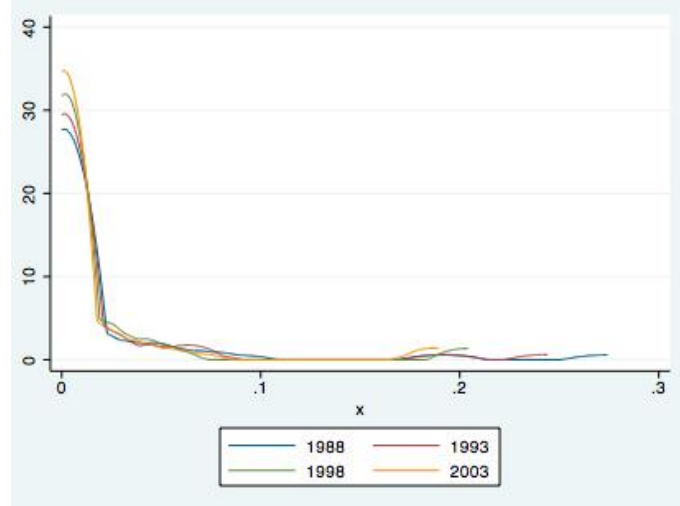

Specialization index

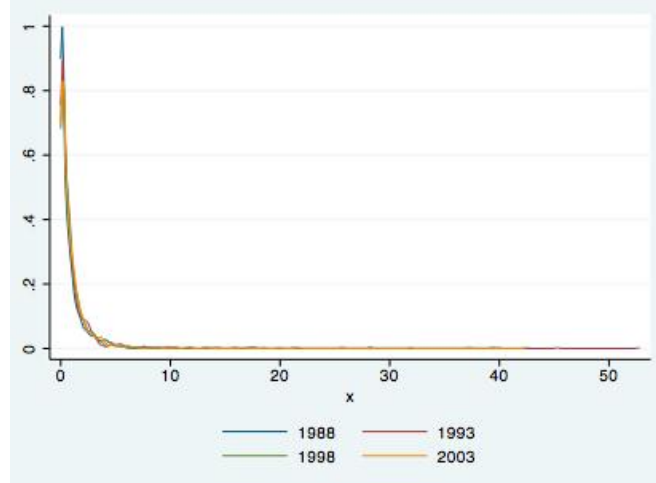

Non-diversity index

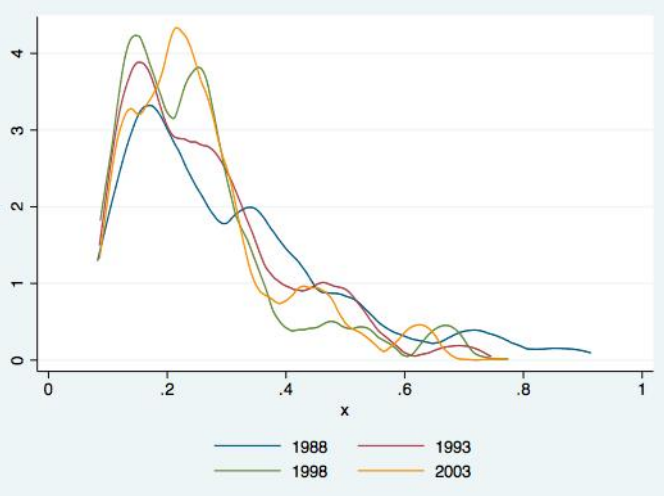

Source: Author's calculations using data from the 1989, 1994, 1999 and 2004 Economic Censuses, INEGI 
Regional and MA fixed effects exhibit a similar pattern to the one analyzed for $\tau=20$. Although the magnitudes differ due to the inclusion of other dummy variables, the sign and significance of the effects is similar to the results of the larger period. This is an expected result, considering that these fixed effects reflect relative advantages or disadvantages that should not change regardless of the length of the period under analysis.

\subsubsection{Technological intensity breakdown}

The SUR estimates by technological-intensity group show that once again the null hypothesis that coefficients are equal for the three groups considered is rejected, which indicates that externalities and market conditions operate in a different way depending on technological intensity (see Table 7).

Comparing the results with the ones presented in Table 4, it is important to highlight the following: (1) in the case of low technology, wages remain significant but in terms of agglomeration factors only the non-diversity index is significant, when in the case of $\tau=20$ Jacobs economies were observed (diversity and competition). (2) For the medium-low technology group, in this case wages are significant and furthermore, their coefficient is higher than the value observed for low technology. For this group, Porter (competition and specialization) externalities appear to be present. (3) For the medium-high technology group, unlike with $\tau=20$, wages are significant but the coefficient has a positive sign (contrary to what is expected), which could indicate that in the short term ( 5 years) these industries tend to grow where wages are higher. Regarding agglomeration economies, unlike the case of $\tau=20$ in which none of the variables were significant, in this case specialization and competition deciles are both significant,and thus consistent with Porter economies.

The equations were estimated by sector and the results show heterogeneity regarding the way market conditions and agglomeration economies operate. In this case, some sectors showed positive coefficients on wages. Considering agglomeration economies, none of the sectors could be classified as MAR, Jacobs or Porter as the variables required for each case were not jointly significant. That is, agglomeration effects are observed, but not in a way consistent with any type of agglomeration economy. 
TABLE 7. SUR ESTIMATES BY TECHNOLOGICAL INTENSITY, $\tau=5$ (STANDARDIZED COEFFICIENTS)

\begin{tabular}{|c|c|c|c|}
\hline $\begin{array}{l}\text { Dependent variable: MA-industry } \\
\text { employment growth }\end{array}$ & Low & Medium-low & Medium-high \\
\hline \multirow[t]{2}{*}{$\begin{array}{l}\text { Employment growth of the same industry } \\
\text { in the rest of the MAs }\end{array}$} & $0.26 * * *$ & $0.39 * * *$ & $0.19 * * *$ \\
\hline & $(9.40)$ & $(5.63)$ & $(4.50)$ \\
\hline \multirow[t]{3}{*}{ Logarithm of real wages int $t-5$} & $-0.07 * *$ & $-0.23 * * *$ & $0.15^{* * * *}$ \\
\hline & $(-2.01)$ & $(-4.27)$ & $(2.70)$ \\
\hline & $039 * * *$ & $-0.58 * * *$ & $-0.76 * * *$ \\
\hline Logarithm of employment in $t-5$ & $(-6.99)$ & $(-7.70)$ & $(-5.47)$ \\
\hline \multirow[t]{2}{*}{ Specialization index of the industry in $t-5$} & 0.01 & $0.13 * *$ & $0.14 * *$ \\
\hline & $(0.59)$ & $(2.46)$ & $(1.67)$ \\
\hline \multirow[t]{2}{*}{ Non-diversity in $t-5$} & $-0.08 *$ & 0.10 & -0.03 \\
\hline & $(-1.89)$ & $(1.02)$ & $(-0.32)$ \\
\hline $\begin{array}{l}\text { Share of the MA in employment of the } \\
\text { maquiladora industry in } t-5\end{array}$ & $\begin{array}{r}0.06 \\
(0.44)\end{array}$ & $\begin{array}{c}0.17 * \\
(1.93)\end{array}$ & $\begin{array}{l}-0.36 * * \\
(-2.43)\end{array}$ \\
\hline \multicolumn{4}{|l|}{ Time effects } \\
\hline \multirow[t]{2}{*}{1998} & $-0.12 * *$ & -0.01 & $-0.25 * *$ \\
\hline & $(-2.38)$ & $(-0.13)$ & $(-2.11)$ \\
\hline \multirow[t]{2}{*}{2003} & $0.27 * * *$ & 0.09 & $-0.49 * * *$ \\
\hline & $(-4.98)$ & $(1.02)$ & $(-3.43)$ \\
\hline \multirow[t]{2}{*}{2008} & $-0.10^{* *}$ & 0.04 & -0.21 \\
\hline & $(-2.01)$ & $(0.49)$ & $(-1.59)$ \\
\hline \multicolumn{4}{|l|}{ Competition deciles } \\
\hline \multirow[t]{2}{*}{4} & -0.19 & $0.20 *$ & 0.26 \\
\hline & $(-1.21)$ & $(1.82)$ & $(1.43)$ \\
\hline \multirow[t]{2}{*}{5} & 0.08 & 0.15 & $0.43 * *$ \\
\hline & $(0.88)$ & $(1.35)$ & $(2.11)$ \\
\hline \multirow[t]{2}{*}{6} & 0.04 & $0.42 * * *$ & $0.34 * * *$ \\
\hline & $(0.61)$ & $(4.75)$ & (2.79) \\
\hline \multirow[t]{2}{*}{7} & 0.08 & $0.33^{* * *}$ & 0.20 \\
\hline & (1.26) & $(4.17)$ & (1.39) \\
\hline \multirow[t]{2}{*}{8} & 0.06 & $0.26 * * *$ & 0.20 \\
\hline & $(1.01)$ & $(3.16)$ & (1.49) \\
\hline \multirow{2}{*}{9} & 0.04 & $0.31 * * *$ & -0.01 \\
\hline & $(0.59)$ & $(4.26)$ & $(-0.10)$ \\
\hline \multirow{2}{*}{10} & -0.05 & $0.41 * * *$ & 0.13 \\
\hline & $(-0.75)$ & (5.08) & (1.05) \\
\hline MA fixed effects & Yes & Yes & Yes \\
\hline \multirow[t]{2}{*}{ Constant } & $1.33^{* * *}$ & $1.09 * *$ & $2.81 * * *$ \\
\hline & (8.14) & $(5.61)$ & $(6.91)$ \\
\hline $\mathrm{N}$ & 1885.00 & 782.00 & 920.00 \\
\hline $\mathrm{p}$ & 0.00 & 0.00 & 0.00 \\
\hline $\mathrm{R}^{2}$ & 0.26 & 0.36 & 0.21 \\
\hline $\begin{array}{l}\text { Chow test of coefficients equality between } \\
\text { groups }\end{array}$ & & $\begin{array}{l}\operatorname{chi} 2(48)=2.1 \mathrm{e}^{\mathrm{0}} \\
\operatorname{Prob}>\operatorname{chi} 2=\end{array}$ & 0.0000 \\
\hline
\end{tabular}




\subsubsection{Determinants of fixed effects}

Considering that behind the MA fixed effects, structural conditions particular to each of them should be at work, the effect of these factors was analyzed. Following the growth literature, variables related to human capital, transportation infrastructure (kilometers of highway) that according to Banerjee, Duflo, and Qian (2009) have an important effect on growth, and financial institutions were analyzed. The last variable seeks to control for the services supply in the MA as well as to identify the effect of the financial system depth in the area on its relative advantages for industrial growth. Due to the lack of information regarding the financial system at the municipality level, the number of commercial banks branches was used as a proxy. (See Appendix 4 for the detail of the information used in this analysis as well as the correlations between these variables).

As Table 8 shows, in the case of low-technology industries, only the number of commercial bank branches appears to have an effect on the relative advantage of the MAs, while for the medium-low technology intensity group, human capital (using the number of literate individuals as a proxy) is significant both included separately and along with the other variables. Transportation infrastructure and bank branches, however, are significant considered separately but once we include both variables, bank branches absorb all the effect.

Finally, for medium-high technology industries, even though all variables are significant considered separately, including the three variables (E12) the only one that remains significant is human capital.

These results are consistent with the literature in which industries with a higher technological level should give more weight to human capital as certain abilities are required in order to take advantage of innovation and new technologies. 
TABLE 8. DETERMINANTS OF MA FIXED EFFECTS BY TECHNOLOGICAL INTENSITY*

\begin{tabular}{|c|c|c|c|c|c|c|c|c|c|c|c|c|}
\hline \multirow{3}{*}{$\begin{array}{l}\text { Share of literate } \\
\text { population }\end{array}$} & \multicolumn{4}{|c|}{ Low } & \multicolumn{4}{|c|}{ Medium-low } & \multicolumn{4}{|c|}{ Medium-high } \\
\hline & E1 & E2 & E3 & $\mathrm{E} 4$ & E5 & E6 & E7 & E8 & E9 & E10 & E11 & E12 \\
\hline & 0.12 & & & 0.09 & $0.19^{* * *}$ & & & $0.12^{* *}$ & $0.34 * * *$ & & & $0.31^{* * *}$ \\
\hline & $(1.60)$ & & & (1.28) & $(3.01)$ & & & $(2.19)$ & $(4.16)$ & & & $(3.71)$ \\
\hline $\begin{array}{l}\text { Km of federal } \\
\text { highway }\end{array}$ & & 0.04 & & 0.02 & & $0.21 * *$ & & 0.13 & & $0.13 * *$ & & 0.01 \\
\hline & & $(0.54)$ & & $(0.64)$ & & (1.99) & & $(1.21)$ & & (2.04) & & $(0.19)$ \\
\hline $\begin{array}{l}\text { Number of } \\
\text { commercial banks }\end{array}$ & & & $0.18 * * *$ & $0.18^{* * *}$ & & & $0.21^{* * *}$ & $0.14^{* * *}$ & & & $0.15^{*}$ & 0.08 \\
\hline & & & $(3.50)$ & (3.36) & & & $(3.21)$ & $(2.86)$ & & & $(1.75)$ & $(1.28)$ \\
\hline Constant & -0.74 & $0.09^{*}$ & $0.09^{* *}$ & -0.56 & $-7.78^{* * *}$ & $-0.68^{* * * *}$ & $-0.36^{* * *}$ & $-5.32 * *$ & $-9.35^{* * * *}$ & $-0.61 * * *$ & $-0.49^{* *}$ & $-8.80 * * *$ \\
\hline & $(-1.41)$ & $(1.67)$ & $(2.11)$ & $(-1.09)$ & $(-3.12)$ & $(-3.15)$ & $(-5.16)$ & $(-2.46)$ & $(-4.53)$ & $(-2.67)$ & $(-2.13)$ & $(-4.09)$ \\
\hline $\mathrm{N}$ & 232 & 232 & 232 & 232 & 232. & 232. & 232 & 232 & 231 & 231 & 231 & 23100 \\
\hline $\mathrm{p}$ & 0.00 & 0.00 & 0.00 & 0.00 & 0.00 & 0.00 & 0.00 & 0.00 & 0.00 & 0.23 & 0.15 & 0.00 \\
\hline $\mathrm{R}^{2}$ & 0.13 & 0.12 & 0.15 & 0.15 & 0.15 & 0.16 & 0.16 & 0.19 & 0.11 & 0.02 & 0.03 & 0.12 \\
\hline
\end{tabular}

\section{Discussion}

The analysis of industrial growth from a geographical perspective, which has not received much attention in the economic literature, can contribute to explain country differences in industrialization processes. It also has policy implications, as consideration of the factors influencing firms' decisions about expansion within a region, could lead to the design of more effective policies to attract investment.

In the case of Mexico, the literature on agglomeration economies and the New Economic Geography has focused on transportation costs and trade opening as the crucial factors that explain industrial location patterns and employment growth. However, industrial movement in the last twenty years seems to indicate that additional factors may be at work: Agglomeration economies, market conditions (wages), and even historical or natural relative disadvantages that affect industrial growth at the regional level.

This paper has analyzed the determinants of regional growth by manufacturing sector for the period of 1988-2008. In the long term, the results show that, for the whole sample, urbanization externalities (Jacobs) are the main factor behind industrial growth in a region. That is, industrial 
diversity in a certain location may create incentives for expanding there. In the short term, however, the main determinant is the initial wage, and the results regarding agglomeration economies indicate that there are Porter externalities. (See Table 9 for a summary of the results)

Applying the same analysis by group of technological intensity and sector, which is the main contribution of this study, there is heterogeneity in the parameters; low-technology sectors are more sensitive to initial wages. Additionally, agglomeration externalities seem to operate in a different way depending on the kind of industry; in general, low-technology sectors exhibit Jacobs dynamic externalities, while high-technology sectors show Porter economies. This means that competition is always beneficial for industrial growth, but low-technology sectors are affected positively by diversity, while high-technology sectors are better off with more specialization. These results are consistent with the idea that high-technology industries require more specific abilities and thus benefit from specialization in the same industry, whereas lowtechnology industries are directed to more urbanized regions, where their markets are.

TABLE 9. SUMMARY OF EFFECTS

\begin{tabular}{|c|c|c|c|c|c|}
\hline & Wages & Competition & Non diversity & Specialization & Possible kind of agglomeration economies** \\
\hline \multicolumn{6}{|c|}{ Whole sample } \\
\hline$\tau=20$ & - & + & - & 0 & Jacobs \\
\hline$\tau=5$ & - & + & 0 & + & Porter \\
\hline \multicolumn{6}{|c|}{ Low technology } \\
\hline$\tau=20$ & - & + & - & 0 & Jacobs \\
\hline$\tau=5$ & - & 0 & - & 0 & - \\
\hline \multicolumn{6}{|c|}{ Medium-low technology } \\
\hline$\tau=20$ & 0 & + & - & + & Jacobs and Porter \\
\hline$\tau=5$ & - & + & 0 & + & Porter \\
\hline \multicolumn{6}{|c|}{ Medium-high technology } \\
\hline$\tau=20$ & 0 & 0 & 0 & 0 & - \\
\hline$\tau=5$ & + & + & 0 & + & Porter \\
\hline
\end{tabular}

The results for the whole sample are consistent with other studies that favor the existence of urbanization economies, such as Glaeser et al. (1992) for the United States, Van Oort (2007) and Van Stel and Nieuwenhuijsen (2004) for the Netherlands, and Batisse (2002) for China. However, in other studies such as De Lucio et al. (2002) for Spain and Acs et al. (2002) for the United States, the results indicate that there are MAR externalities, even though these last 
authors focus on high-technology sectors which, as shown in Section 5, analyzed separately, exhibit not urbanization but rather Porter economies (specialization and competition).

The analysis of regional particular characteristics shows that, controlling for market conditions, agglomeration effects, initial conditions and national demand growth, the south, the center, and the Gulf of Mexico have a relative disadvantage for growth in medium-high technology sectors that cannot be compensated by changes in agglomeration variables. This means that there are structural factors that make growth difficult for this kind of industry. Performing this same analysis at the MA level, only one of 58 areas considered shows an advantage for medium-high technology goods. This indicates limitations in the capacity for attracting medium-high technology industries.

Finally, the analysis of fixed effects or relative advantages suggests that additional financial services and transportation infrastructure increase these advantages for low and medium-low technology sectors, with the latter group also affected by the stock of human capital in the MA. However, the only factor capable of reducing disadvantages in medium-high technology sectors is human capital. These results have further policy implications regarding the direction of public investment, depending on the type of industries that a region intends to attract.

This paper is a first approach to the determinants of regional industrial growth, it is important to expand this analysis in different dimensions. First, even though this study incorporates geography through fixed and regional effects, it implicitly assumes that geographical units (MAs) are independent. That is, it does not allow for positive externalities from proximity to other units -what Anselin, Le Gallo, and Jayet (2008) call spatial dependency. It is thus important to extend this work to consider the interaction between different geographical areas. Second, it would be appropriate to replicate this work as a sensitivity analysis for different geographical and sectoral groupings as the effects of knowledge spillovers tend to strengthen as more disaggregated geographical units are used (Van Oort, 2007). Finally, although the OECD establishes different technological intensity groups exogenously, these groups should differ between countries: A high-technology sector for one country could be medium-technology for another, due to the differences in production processes. Taken together, these considerations suggest more complex models in which alternative definitions should be studied. 


\section{References}

Acs, Z. J., FitzRoy, F. R., \& Smith, I. (2002). "High-technology employment and R\&D in cities: heterogeneity vs specialization." The Annals of Regional Science, 36(3), 373-386.

Amiti, M., \&Cameron, L. (2007). "Economic geography and wages."Review of Economics and Statistics, 89(1): 15-29.

Anselin, L., Le Gallo, J.,\& Jayet, H. (2008). "Spatial panel econometrics” in Mátyás, L., y Sevestre, P. (Eds.) The Econometrics of Panel Data, Fundamentals and Recent Developments in Theory and Practice(3rd Edition)(pp. 625-665). Berlin: Springer.

Banerjee, A., Duflo, E.,\& Qian, N. (2009). "On the Road: The Effect of Transportation Networks in China." Yale University Working Paper.

Batisse, C. (2002). "Dynamic externalities and local growth: A panel data analysis applied to Chinese provinces." China Economic Review, 13: 231-251.

Blundell, R., \& Bond, S. (1998). "Initial conditions and moment restrictions in dynamic panel data models." Journal of econometrics, 87(1), 115-143.

De Lucio, J.J., Herce, J.A., \&Goicolea, A. (2002). "The effects of externalities on productivity growth in Spanish industry."Regional Science and Urban Economics, 32: 241-258.

Diaz-Bautista, A. (2005). "Agglomeration Economies, Economic Growth and the New Economic Geography in Mexico."EconoQuantum, 1(2): 57-79.

Durlauf, S. N., Johnson, P. A., \& Temple, J. R.W. (2005). "Growth Econometrics." In Aghion, P. y Durlauf, S.N. (Eds.), Handbook of Economic Growth (Vol 1.: pp. 555-677). North Holland.

Esquivel, G., Lustig, N., \& Scott, J. (2010). "A Decade of Falling Inequality in Mexico: Market Forces or State Action?" Discussion Paper UNDP. Poverty Reduction.

Félix Verduzco, G. (2005). "Apertura y ventajas territoriales: análisis del sector manufacturero en México.”Estudios Económicos, 20(1): 109-136

Fujita, M., Krugman, P. R., \& Venables, A. (1999). The spatial economy cities, regions and international trade. Cambridge, MA: MIT Press.

Gabaix, X. (1999). “Zipf's Law and the Growth of Cities.”American Economic Review, 89(2): 129-132.

Glaeser, E.L. (2010). Agglomeration Economics. Chicago, IL: University of Chicago Press.

Glaeser, E.L., \& Gottlieb, J. D. (2009). "The wealth of cities: Agglomeration economies and spatial equilibrium in the United States." Journal of Economic Literature, 47(4): 983-1028.

Glaeser, E. L., Kallal, H. D., Scheinkman, J. A., \&Shleifer, A. (1992). "Growth in Cities.”Journal of Political Economy, 100(6): 1126-1152.

Griliches, Z. (1979). "Issues in assessing the contribution of R\&D to productivity growth." Bell Journal of Economics, 10:92-116

Hanson, G. (1998). "Regional adjustment to trade liberalization."Regional Science and Urban Economics, 28: 419-444.

Hanson, G. (2003). "What Has Happened to Wages in Mexico Since NAFTA?" NBER Working Paper, w9563. 
Harris, R. (2011). “Models of Regional Growth: Past, Present and Future.”Journal of Economic Surveys, 25(5): 913-951

Henderson, V., Kuncoro, A., \& Turner, M. (1995). "Industrial Development in Cities." Journal of Political Economy, 103(5): 1067-90.

INEGI (1989). 1989 Economic Census. Retrieved from www.inegi.org.mx

INEGI (1994). 1994 Economic Census. Retrieved from www.inegi.org.mx

INEGI (1999). 1999 Economic Census. Retrieved from www.inegi.org.mx

INEGI (2004). 2004 Economic Census. Retrieved from www.inegi.org.mx

INEGI (2009). 2009 Economic Census. Retrieved from www.inegi.org.mx

Jacobs, J. (1969). The Economy of Cities. New York: Random House

Jaffe, A.B. (1989). "Real effects of academic research.” American Economic Review, 79(5): 957-970.

Krugman, P. (1991). Geography and Trade. Cambridge, MA: MIT Press.

Krugman, P., \&Livas, R. (1996). “Trade Policy and the Third World Metropolis.”Journal of Development Economics, 49(1): 137-150.

Krugman, P.,\& Venables, A. (1995). "Globalization and the inequality of nations." Quarterly Journal of Economics, 110: 857-880.

Marshall, A. (1890). Principles of Economics. London: Macmillan and Co.

Mendoza-Cota, J.E. (2002). "Agglomeration Economies and Urban Manufacturing Growth in the Northern Border Cities of Mexico.”Economía Mexicana, XI(1).

Mendoza-Cota, J.E., \&Pérez-Cruz, J.A. (2007). "Aglomeración, encadenamientos industriales y cambios en la localización manufacturera en México.”Economía, sociedad y territorio, VI(23): 655-691.

Moretti, E. (2011). "Local Labor Markets.”In Ashenfelter, O. y Card, D. (Eds.), Handbook of Labor Economics(Vol 4.: pp. 1237-1313). North Holland.

OECD(2003). OECD Science, Technology and Industry Scoreboard, Annex 1.

Paci, R., \& Usai, S. (2000). "Externalities, Knowledge Spillovers and the Spatial Distribution of Innovation.” ERSA conference papers, European Regional Science Association.

Porter, M.E. (1990). The Competitive Advantage of Nations. New York: Free Press.

Rodrik, D. (2004). "Industrial Policy for the twenty-first Century." Working Paper Series, Harvard University, John F. Kennedy School of Government. RWP 04-047.

Soloaga, I., Lara, G., \& Wendelspiess, F. (2010). "Determinantes de la migración interestatal en México: 1995-2000 y 2000-2005", in Yunez, A. (ed.) Los Grandes Problemas de México, Tomo X. Economía Rural. México, D.F.: El Colegio de México.

Van Oort, F.G. (2007). "Spatial and sectoral composition effects of agglomeration economies in the Netherlands."Papers in Regional Science, 86: 5-30.

Van Stel, A.J.,\& Nieuwenhuijsen, H.R. (2004). “Knowledge spillovers and economic growth: an analysis using data of Dutch regions in the period 1987-1995." Regional Studies, 38(4): 393-407. 


\section{Appendix1 MAs and regional structure}

FIGURE 16. MAS STRUCTURE

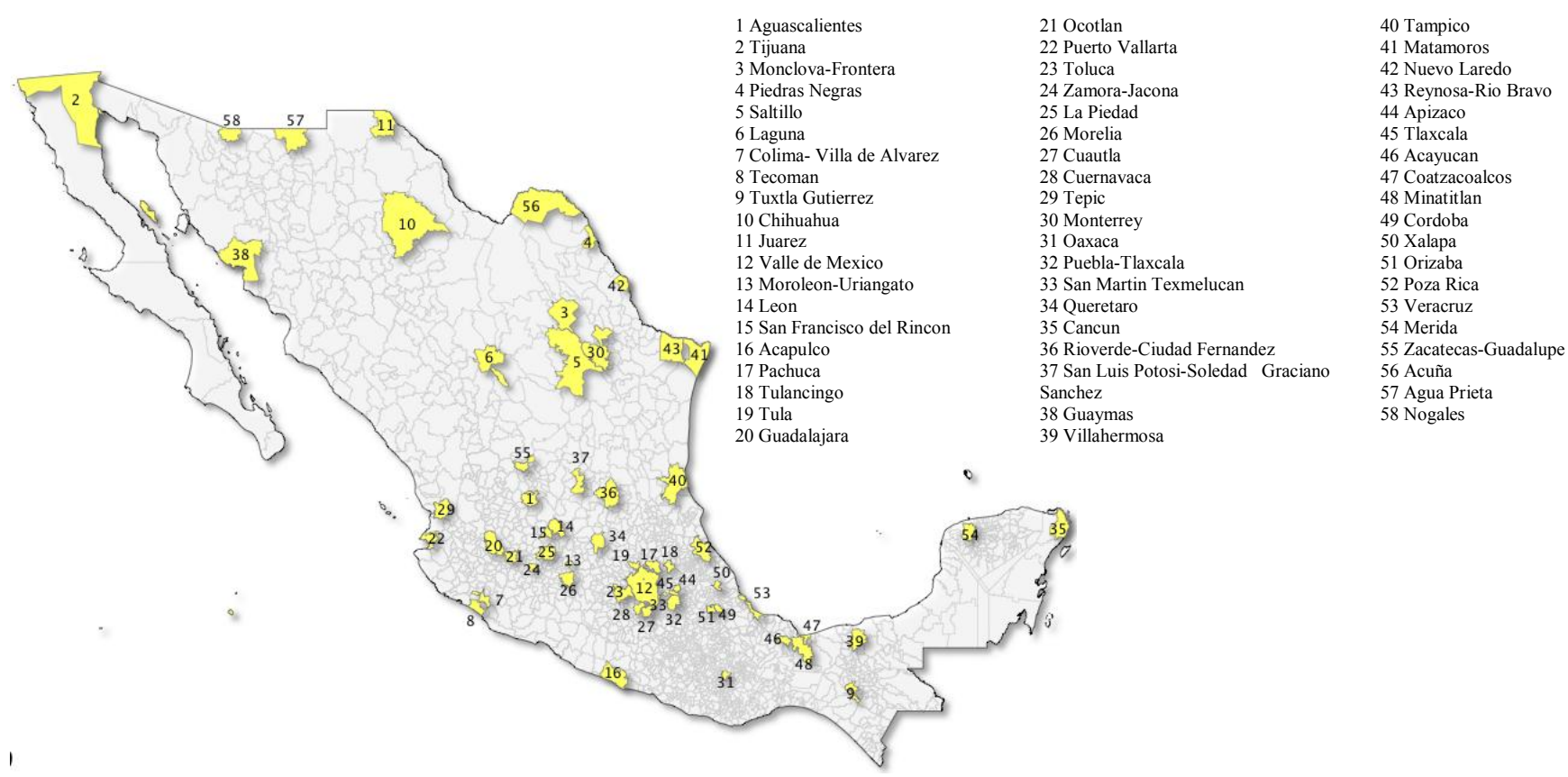

FIGURE 17. REGIONAL STRUCTURE*

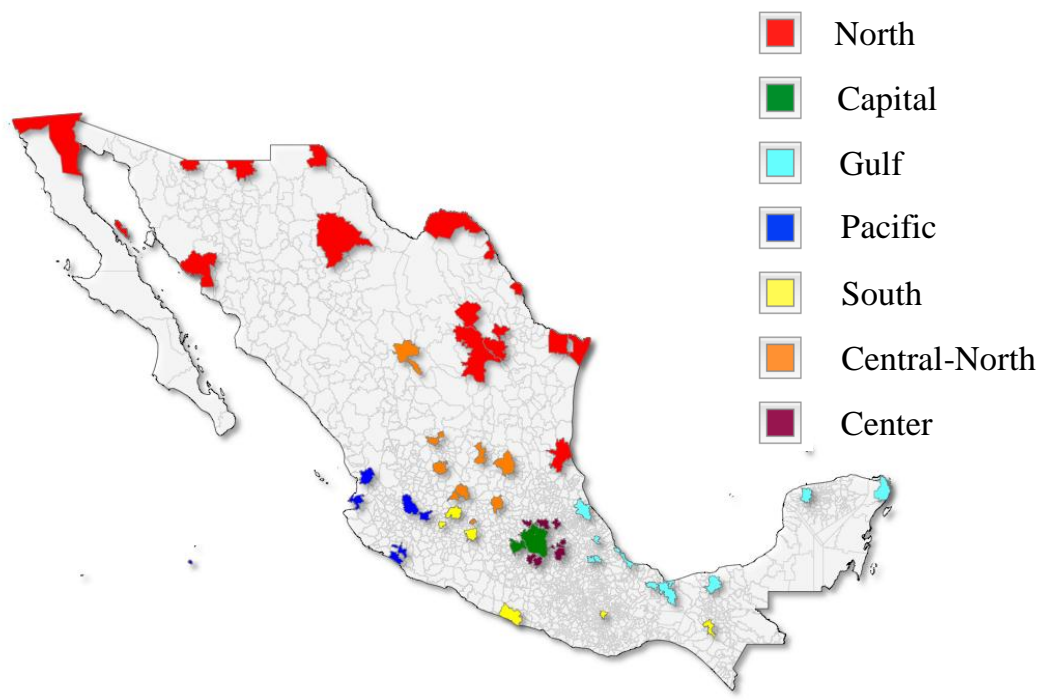

Capital: Distrito Federal and Estado de Mexico; Center: Hidalgo, Morelos, Puebla and Tlaxcala; CentralNorth: Aguascalientes, Durango, Guanajuato, Queretaro, San Luis Potosi and Zacatecas; Gulf: Campeche, Quintana Roo, Tabasco, Veracruz and Yucatan; North: Baja California, Coahuila, Chihuahua, Nuevo Leon, Sonora and Tamaulipas; Pacific: Baja California Sur, Colima, Jalisco, Nayarit and Sinaloa; South: Chiapas, Guerrero, Michoacán and Oaxaca

*When an MA included two or more municipalities from different states that correspond to different regions, it was classified according to the state that concentrated most of the employment.

Source: Author's calculations using data from INEGI. 


\section{Appendix2 Structure of the 18 manufacturing sectors considered}

\section{TABLE 10. STRUCTURE OF THE SECTORS CONSIDERED BY PRODUCT CLASSIFICATION}

\begin{tabular}{lll}
\hline \multicolumn{1}{c}{ Sector } & \multicolumn{1}{c}{ 1988- CMAP codes } & 2008-NAICS codes \\
\hline Food, beverages and tobacco & $311,312,313$ y 314 & 311,312 \\
Textile & $3211,3212,3213$ & 313,314 \\
Apparel & 3214,3220 & 315 \\
Leather and footwear & 323,324 & 316 \\
Wood & 331 & 321 \\
Paper & 341 & 322 \\
Printing & 342 & 323 \\
Oil and coal products & 353,354 & 324 \\
Transportation equipment & 3841,3842 & 336 \\
Computer and telecommunication & $3823,3832,3850$ & 334 \\
equipment, electronic components and & & \\
accessories & 3831,3833 & \\
Electric apparatus & 3821,3822 & 335 \\
Machinery and equipment & 351,352 & 333 \\
Chemical industry & 355,356 & 325 (Except 3254$)$ \\
Plastic and rubber & $361,362,369$ & 326 \\
Non-metallic mineral products & $371,372,389$ & 327 \\
Primary metal manufacturing and metal & & 331,332 \\
products & 332 & 337 \\
Furniture and mattresses & 3900 & 339 \\
Other industries & &
\end{tabular}

\section{Appendix3 OECD classification by technological intensity (ISIC rev. 3)}

This classification is based on the analysis of Research and Development (R\&D) expenses, as well as the production of twelve members of the OECD during 1991-1999. The ISIC REV. 3 and input-output matrices are used.

The classification of manufacturing sectors in high-technology, medium-high technology, medium-low technology and low technology was made after sorting the different industries according to their average for 1991-1999. There were also considered: i) temporal stability, that is, that for adjacent years industries classified under the highest categories had more intensity than the ones classified in the lowest categories. ii) country median stability which means that industries classified to the higher categories have a higher median intensity than those in lower categories.

Even though this classification considers four categories, in the case of high-technology only a handful of sectors appear in this category. Therefore, the two higher technology groups were considered as one: 
TABLE 11. PRODUCTS CLASSIFICATION BY TECHNOLOGICAL INTENSITY

\begin{tabular}{lll}
\hline \hline \multicolumn{1}{c}{ Low intensity } & \multicolumn{1}{c}{ Medium-low intensity } & \multicolumn{1}{c}{ Medium-high intensity } \\
\hline Food, beverages and tobacco & Petroleum and coal products & Machinery and equipment \\
Textiles & manufacturing & Transportation equipment \\
Apparel & Plastic and rubber & Computers and electronics \\
Leather and footwear & Non-metallic mineral products & Electric apparatus \\
Wood & Primary metal manufacturing and metal & Chemical products \\
Paper & products & \\
Printing & & \\
Furniture and mattresses & & \\
Other industries & & \\
\hline \hline
\end{tabular}

Source:Author's elaboration with information from the OECD.

\section{Appendix 4 Data used in estimates of the determinants of MA fixed effects}

The percentage of people with more than 15 years who is literate was used as a proxy of average human capital in the MA. This variable was obtained from the 1990 and 2000 Housing and Population Censuses, as well as the 1995 and 2005 Population Counts. This information was used to approximate the period required according to the Economic Censuses: The 1990 Population Census was used for the 1988 Economic Census; the 1995 Population Count for the 1993 Economic Census; the 2000 Population Census for the 1998 Economic Census and the 2005 Population Count for the 2003 Economic Census.

Even though from these sources the share of population older than 18 with more than six years of education, this information was not used as this indicator did not appear as such in the Population Counts and the methodology was different. Additionally a correlation between this indicator and the literate population of 78\% was found for all the Census and Counts.

In the case of highway infrastructure, the length of federal highways (in kilometers) from the State and Municipal System of Databases (SIMBAD for its initials in Spanish), INEGI. The indicator for the highway network length was also obtained and its correlation with the length of federal highway was of $77 \%$.

Finally, for the indicator of financial services supply, the number of commercial banks branches was used, using also SIMBAD, INEGI as source. 


\section{TABLE 12. CORRELATION MATRIX OF VARIABLES RELATED WITH FIXED EFFECTS}

\begin{tabular}{|c|c|c|c|c|c|c|}
\hline & $\begin{array}{c}\text { FE low } \\
\text { technology }\end{array}$ & $\begin{array}{l}\text { FE medium- } \\
\text { low technology }\end{array}$ & $\begin{array}{l}\text { FEmedium-high } \\
\text { technology }\end{array}$ & $\begin{array}{c}\text { Share of literate } \\
\text { population }\end{array}$ & $\begin{array}{c}\text { Km of federal } \\
\text { highway }\end{array}$ & $\begin{array}{c}\text { Number of } \\
\text { commercial } \\
\text { banks }\end{array}$ \\
\hline FE low-technology & 1 & & & & & \\
\hline FE medium-low technology & -0.0285 & 1 & & & & \\
\hline \multirow{2}{*}{$\begin{array}{l}\text { FE medium-high technology } \\
\text { Share of literate population }\end{array}$} & 0.0984 & 0.1462 & 1 & & & \\
\hline & 0.0780 & 0.1685 & 0.3110 & 1 & & \\
\hline Kmof federal highway & 0.0494 & 0.2001 & 0.1293 & 0.2857 & 1 & \\
\hline Number of commercial banks & 0.1750 & 0.1840 & 0.1471 & 0.2444 & 0.3469 & 1 \\
\hline
\end{tabular}

Source: Author's calculation with data from the 1989. 1994, 1999, 2004 and 2009 Economic Censuses, SIMBAD, the 1990 and 2000 Population and Housing Censuses and the 1995 and 2005 Population Counts, INEGI. 